\title{
Tomato SIPUB24 enhances resistance to Xanthomonas euvesicatoria pv. perforans race T3
}

\author{
Xin Liu ${ }^{1,2}$, Ge Meng ${ }^{1,2}$, Mengrui Wang ${ }^{1,2}$, Zilin Qian ${ }^{1,2}$, Yaxian Zhang ${ }^{1,2}$ and Wencai Yang (1) ${ }^{1,2}$
}

\begin{abstract}
Solanum lycopersicum var. cerasiforme accession PI 114490 has broad-spectrum resistance to bacterial spot caused by several species of Xanthomonas. Resistance is quantitatively inherited, and a common quantitative trait locus QTL-11B on chromosome 11 has been identified previously. In this study, the SIPub24 gene was characterized in QTL-11B. SIPub24 in PI 114490 was upregulated by infection with X. euvesicatoria pv. perforans race T3, but its transcription was low in the susceptible line $\mathrm{OH} 88119$ whether or not it was infected by the pathogen. The differential expression of SIPub24 between PI 114490 and $\mathrm{OH} 88119$ was due to great sequence variation in the promoter region. The promoter of SIPub24 in OH 88119 had very low activity and did not respond to pathogen infection. Transgenic lines of OH 88119 overexpressing SIPub24 isolated from PI 114490 showed significantly enhanced resistance, while mutants of Slpub24 generated by CRISPR/Cas9 editing showed more susceptibility to race T3 and to other races. The mutants also showed spontaneous cell death in leaves. The expression of the salicylic acid (SA) pathway gene phenylalanine ammonia-lyase (PAL) and signaling-related genes pathogenesis-related (PR1) and nonexpresser of PR1 (NPR1) were influenced by SIPub24. The content of SA in tomato plants was consistent with the level of SIPub24 expression. Furthermore, SIPUB24 interacted with the cell wall protein SICWP and could regulate the degradation of SICWP. The expression levels of SICWP and SICWINV1, a cell wall invertase gene, showed opposite patterns during pathogen infection. The activity of SICWINV1 was lower in mutants than in PI 114490. The results are discussed in terms of the roles of the abovementioned genes, and a potential model for SIPUB24-mediated resistance to bacterial spot is proposed.
\end{abstract}

\section{Introduction}

Bacterial spot caused by Xanthomonas euvesicatoria pv. euvesicatoria (race T1), X. vesicatoria (race T2), X. euvesicatoria pv. perforans (races T3 and T4), and X. cynarae pv. gardneri is a widespread disease in tomato production $^{1-3}$. The disease can cause severe yield loss and fruit quality reduction in tomato ${ }^{4,5}$. Although the use of resistant varieties is the most effective approach for control of the disease, the existence of multiple species of Xanthomonas and quick shifts of species/races in the same region are among the most important causes of unsuccessful management of the disease $\mathrm{e}^{4-6}$. Therefore,

Correspondence: Wencai Yang (yangwencai@cau.edu.cn)

${ }^{1}$ Beijing Key Laboratory of Growth and Developmental Regulation for Protected Vegetable Crops, Department of Vegetable Science, China

Agricultural University, Beijing 100193, China

${ }^{2}$ Joint Laboratory for International Cooperation in Crop Molecular Breeding,

Ministry of Education of the People's Republic of China, Beijing 100193, China sources with more durable and broad-spectrum resistance to the disease are desirable for developing new cultivars.

Several studies have indicated that Solanum lycopersicum var. cerasiforme accession PI 114490 may provide broad-spectrum resistance to all species and races of Xanthomonas causing bacterial spot in tomato ${ }^{7-9}$. The resistance to races T1-T4 and X. cynarae pv. gardneri in PI 114490 is quantitatively inherited, and several quantitative trait loci (QTLs) have been reported ${ }^{7-13}$. Classical genetic analyses based on segregation of resistance in $F_{2}$ and inbred backcross (IBC) populations derived from PI 114490 suggest that its resistance to race $\mathrm{T} 2$ is conditioned by two to four loci ${ }^{8}$. The high correlation between race $\mathrm{T} 1$ and race $\mathrm{T} 2$ resistance in the $\mathrm{IBC}$ population suggests that there are common loci for resistance to both races, while the poor correlation of resistance between races $\mathrm{T} 2$ and $\mathrm{T} 3$ indicates that resistance to all species and races is not controlled by the same genes in PI $114490^{8}$.

\section{(c) The Author(s) 2021}

(c) Open Access This article is licensed under a Creative Commons Attribution 4.0 International License, which permits use, sharing, adaptation, distribution and reproduction cc) in any medium or format, as long as you give appropriate credit to the original author(s) and the source, provide a link to the Creative Commons license, and indicate if changes were made. The images or other third party material in this article are included in the article's Creative Commons license, unless indicated otherwise in a credit line to the material. If material is not included in the article's Creative Commons license and your intended use is not permitted by statutory regulation or exceeds the permitted use, you will need to obtain permission directly from the copyright holder. To view a copy of this license, visit http://creativecommons.org/licenses/by/4.0/. 
However, a common locus on chromosome 11 conferring resistance to races $\mathrm{T} 2, \mathrm{~T} 3$, and $\mathrm{T} 4$ has been identified in the same IBC population ${ }^{13}$. The common locus conferring resistance to races $\mathrm{T} 3$ and $\mathrm{T} 4$ has also been confirmed in later studies using the same IBC population and other segregating populations ${ }^{10,12}$. Recent studies indicate that the common locus on chromosome 11, designated QTL$11 B$, confers resistance to races $\mathrm{T} 1-\mathrm{T} 4$ and $X$. cynarae $\mathrm{pv}$. gardneri $^{7,9}$. All these data suggest that $Q T L-11 B$ in PI 114490 confers resistance to all races and species. Previous studies have shown that the Solyc11g068940 gene, encoding a plant U-box protein (designated SIPUB24 in this study), in the QTL-11B region of PI 114490 is highly induced by the presence of the race T3 $\operatorname{strain}^{14,15}$, suggesting that it may participate in resistance to race T3.

E3 ubiquitin (Ub) ligases are key regulators in plants for defense during both PAMP-triggered immunity (PTI) and effector-triggered immunity (ETI). Their regulation can be either positive or negative depending on the plantpathogen system and usually involves the production of hydrogen peroxide $\left(\mathrm{H}_{2} \mathrm{O}_{2}\right)$ and salicylic acid (SA). SPL11 in rice, the first characterized U-box E3 ligase, acts as a negative regulator of plant programmed cell death (PCD) and pathogenic defense. The spl11 mutant shows spontaneous cell death in leaves and confers enhanced resistance to rice blast and bacterial blight ${ }^{16,17}$. PUB13, the closest ortholog of SPL11 in Arabidopsis, negatively regulates resistance to the biotrophic pathogens Pseudomonas syringae pv. maculicola and Erysiphe cichoracearum but positively regulates resistance to the necrotrophic fungal pathogens Botrytis cinerea and Alternaria brassicicola. The spontaneous cell death and elevated $\mathrm{H}_{2} \mathrm{O}_{2}$ accumulation in the pub13 mutant depend on the SA signal $^{18,19}$. PUB22, PUB23, and PUB24 in Arabidopsis act as negative regulators of PTI in response to several distinct PAMPs. The triple mutant pub22/pub23/pub24 exhibits enhanced resistance to diverse pathogens, accompanied by oxidative burst and plant cell death ${ }^{20,21}$. PUB17, a U-box ARM repeat E3 ligase conserved in Arabidopsis, Nicotiana benthamiana, tomato and potato $^{22,23}$, is a positive regulator of cell death and plant disease resistance. Another conserved class of U-box E3 ligases, including CMPG1 in Petroselinum crispum $^{24}$, PUB20 and PUB21 in A. thaliana ${ }^{25}$, CMPG1-V in Haynaldia villosa ${ }^{26}$, NtCMPG1 in N. tabacum, and SlCmpg1 in tomato ${ }^{27}$, also act as positive regulators of plant disease resistance. The pepper E3 ubiquitin ligase CaRING1 is a positive regulator of resistance and is required for cell death and the SA-dependent defense response to hemibiotrophic Pseudomonas syringae pv. tomato and biotrophic Hyaloperonospora arabidopsidis infections ${ }^{28}$. In apple fruits, two ubiquitin E3 ligases regulate the immune response with opposing functions. The U-box E3 ligase MdPUB29 is a positive regulator of the defense response to the fungal pathogen Botryosphaeria dothidea, possibly regulating the SA pathway ${ }^{29}$, while the BTB-BACK domain E3 ligase MdPOB1 ubiquitinates and degrades MdPUB29, resulting in suppression of defense against $B$. dothidea ${ }^{30}$.

Here, we reported that U-box E3 ligase protein 24 (SIPUB24) acted as a positive regulator of resistance to bacterial spot in tomato. The knockout mutants also exhibited spontaneous cell death in leaves. The increase in plant pathogen defense was correlated with the SA biosynthesis pathway and signaling. In addition, SIPUB24 targeted the potential cell wall protein SlCWP. A model is proposed to provide additional understanding of the Ubox-mediated response to disease.

\section{Results}

Sequence variation in SIPub24 between PI 114490 and $\mathrm{OH}$ 88119

The genomic DNA sequence of the SlPub24 gene was obtained by PCR amplification using gene-specific primers (Table S1). It was $1278 \mathrm{bp}$ in the resistant line PI 114490 and $1272 \mathrm{bp}$ in the susceptible line $\mathrm{OH} 88119$. Full-length cDNA was obtained by RT-PCR and RACE. A 1457-bp fragment and a 1451-bp fragment were obtained for PI 114490 and $\mathrm{OH} 88119$, respectively. Alignment of genomic DNA and cDNA sequences revealed that there was no intron in the gene. There were two single nucleotide polymorphisms (SNPs) and one 6-bp (GTAATA) insertion/deletion (InDel) in the coding region (Fig. 1a) and no sequence variation in the $5^{\prime} \mathrm{UTR}(86 \mathrm{bp})$ or $3^{\prime} \mathrm{UTR}$ (93 bp) between PI 114490 and $\mathrm{OH}$ 88119. A comparison of deduced amino acid sequences showed that the 6-bp InDel resulted in two amino acid losses in $\mathrm{OH}$ 88119, while C272T was a nonsynonymous substitution (T91I), and A549C was a synonymous substitution (Fig. 1b). A U-box domain at the $\mathrm{N}$-terminus of the deduced protein sequence between amino acids 9 and 79 (25-237 bp in cDNA sequence, Fig. 1a) was predicted with SMART (http://smart.embl-heidelberg.de/). Phylogenetic analysis indicated that the deduced protein was closely related to AtPUB24 in Arabidopsis (Fig. 1c), which confirmed the nomenclature of SIPUB24. A BLAST search of SIPUB24 in the tomato genome ITAG release 4.0 (https://solgenomics. net/) identified four genes annotated as U-box domaincontaining protein 24 (Fig. 1c), but their coding sequences were quite different (Fig. S1).

\section{SIPUB24 is a ubiquitous protein}

The subcellular localization of the SIPUB24 protein was determined by Agrobacterium-mediated transient expression of the SlPub24 gene in tomato protoplast and onion epidermal cells. The SIPUB24-GFP fusion protein was detected in the cytoplasm, plasma membrane, and nucleus in tomato cells (Fig. 2a), and this localization was 

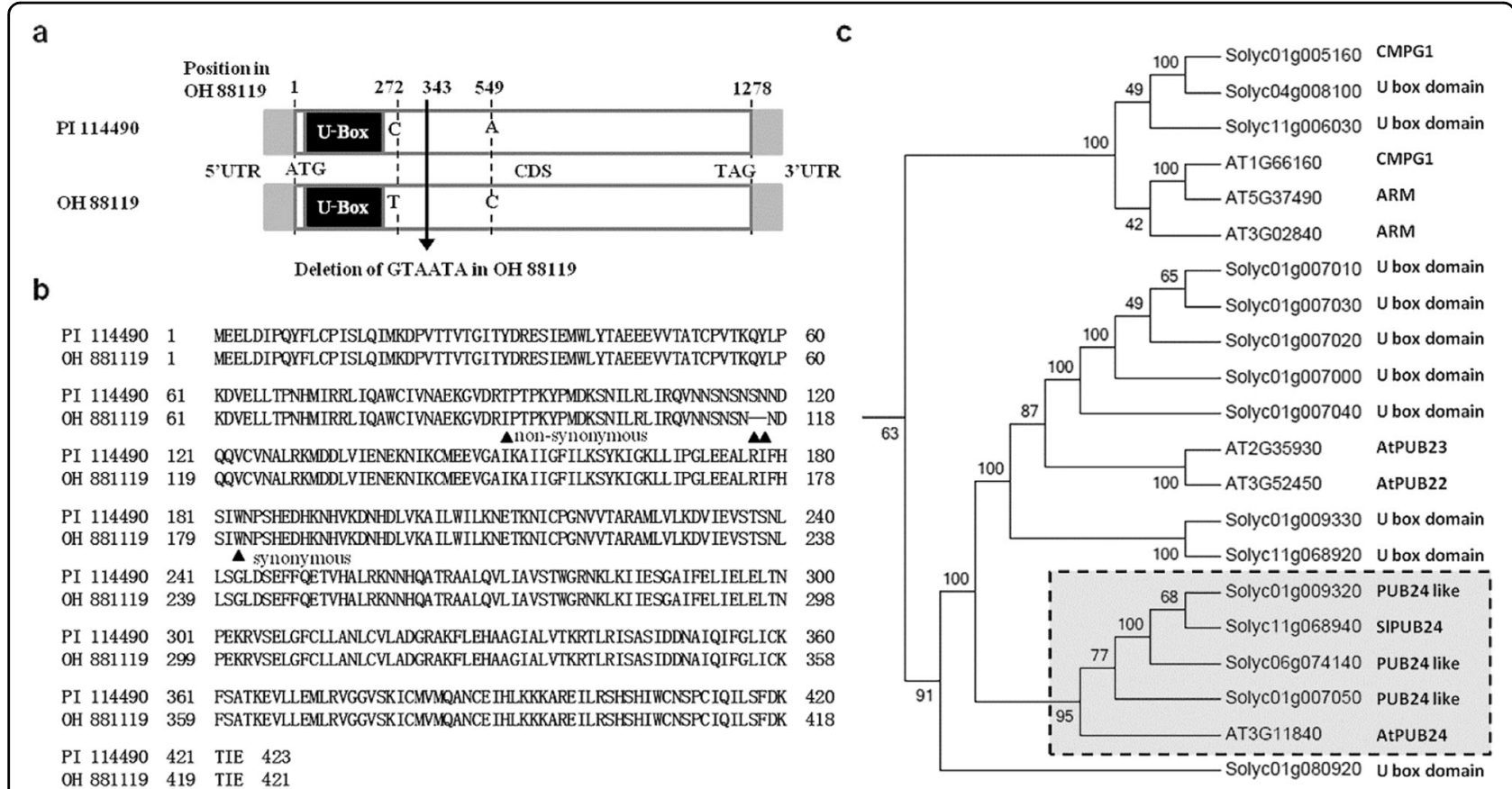

Fig. 1 Comparison of SIPub24 sequences between the resistant line PI 114490 and the susceptible line OH 88119 , as well as phylogenetic analysis of SIPUB24. a Diagram shows differences in coding sequences of SIPub24 between PI 114490 and OH 88119 . b Alignment of deduced amino acid sequences of SIPUB24 between PI 114490 and OH 88119. $\mathbf{A}$ indicates the amino acid substitution or insertion/deletion positions. c Phylogenetic analysis of SIPUB24 with various U-box type E3 ubiquitin ligases in Solanum lycopersicum and Arabidopsis thaliana

confirmed by observation of the SIPUB24-GFP fusion protein during plasmolysis of onion epidermal cells (Fig. 2b). These data suggested that SIPUB24 is a ubiquitous protein.

\section{Transgenic overexpression of SIPub24 in $\mathrm{OH} 88119$ enhances resistance to $X$. euvesicatoria pv. perforans race $\mathrm{T} 3$}

To determine the role of the SlPub24 gene in PI 114490 in resistance to $X$. euvesicatoria $\mathrm{pv}$. perforans race T3 strain Xv829, two constructs, SIPub24PI (Fig. S2a) and pSlPub24PI (Fig. S2b), were developed for overexpression of the gene in the susceptible tomato line $\mathrm{OH} 88119$. A total of 12 independent transgenic lines for the construct SlPub24PI and 4 independent transgenic lines for the construct pSlPub24PI were obtained. Four transgenic lines, SIPub24PI-\#13-1, SIPub24PI-\#13-2, pSIPUB24PI\#34-2, and pSlPub24PI-\#35-10, were used in the following experiments. All transgenic plants had fewer disease lesions on leaves than $\mathrm{OH} 88119$ plants at 9 days post inoculation (dpi) (Fig. 3a). The percentage of diseased leaf area was significantly $(P<0.05)$ lower in the three transgenic lines SlPub24PI-\#13-2, pSlPub24PI-\#34-2, and pSlPub24PI-\#35-10 than in OH 88119 (Fig. 3b), and the bacterial populations were significantly $(P<0.05)$ smaller in all transgenic lines than in $\mathrm{OH} 88119$ (Fig. 3c). The leaves of transgenic plants had less necrotic tissue than
$\mathrm{OH} 88119$ (Fig. 3d). The transgenic lines carrying the SlPub24 gene with its native promoter from PI 114490 (construct pSIPub24PI) were more resistant than the transgenic lines carrying only SlPub24 from PI 114490 (construct SlPub24PI), suggesting that the native promoter and UTRs might enhance the resistance.

\section{Mutation of SIPub24 in PI 114490 by CRISPR/Cas9 editing} increases susceptibility to $X$. euvesicatoria pv. perforans race $\mathrm{T} 3$ and induces spontaneous cell death in leaves

The SlPub24 gene was mutated in PI 114490 at two target sites (Fig. 4a) using the CRISPR/Cas9 editing system to further validate the role of SlPub24 in resistance to $X$. euvesicatoria pv. perforans race T3. Three mutated lines (SlPub24PI-Cri-\#53, SlPub24PI-Cri-\#54, and SIPub24PI-Cri-\#45) were obtained. The line SlPub24PICri- $\# 53$ had two types of mutations in the target 2 region in T1 progenies: a 1-bp deletion in line SlPub24PI-Cri\#53-1 and a 7-bp deletion in line SlPub24PI-Cri-\#53-6. Line SlPub24PI-Cri-\#54 had a 4-bp deletion in the target 1 region, and line SlPub24PI-Cri-\#45 had a T insertion in the target 1 region and a 7-bp deletion in the target 2 region (Fig. 4b). Leaves of mutants showed more disease lesions than those of PI 114490 (Fig. 4c). The percentage of diseased leaf area (Fig. 4d) and bacterial populations in leaves (Fig. 4e) were significantly $(p<0.01)$ higher in mutants than in PI 114490 at $7 \mathrm{dpi}$ and $9 \mathrm{dpi}$, respectively. 
a

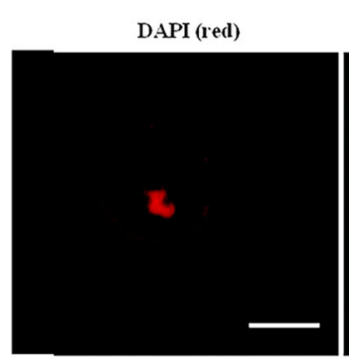

b
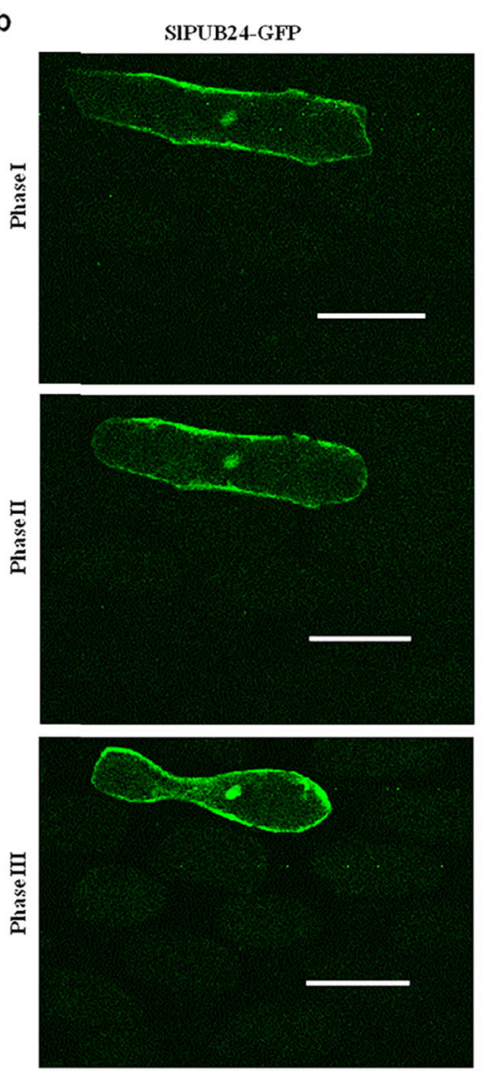

SIPUB24-GFP
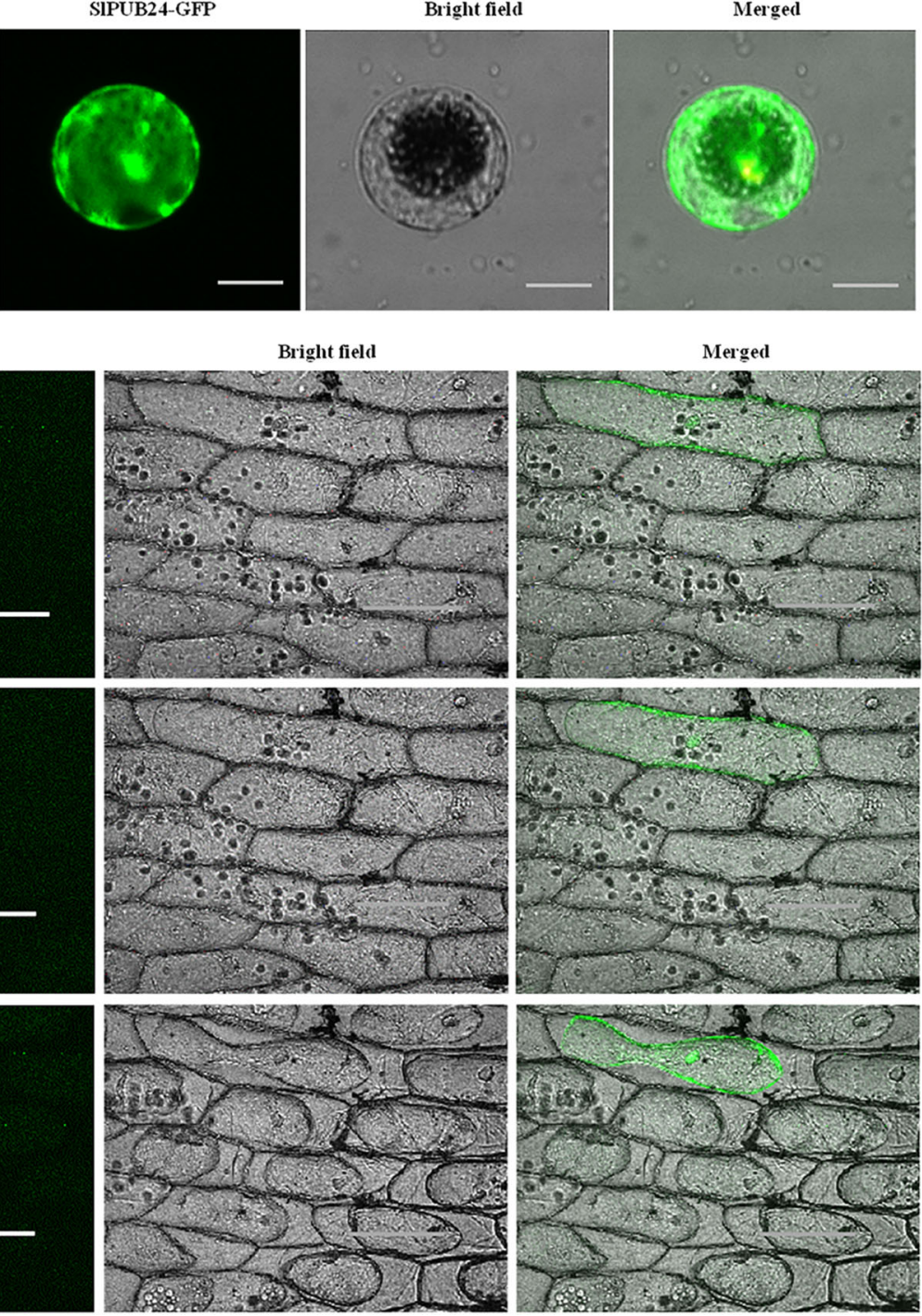

Fig. 2 Subcellular localization of SIPUB24. a Subcellular localization of SIPUB24-GFP in tomato protoplasts isolated from tomato line PI 114490. b Dynamic observation of subcellular localization of SIPUB24-GFP in onion epidermal cells infiltrated with $0.3 \mathrm{~g} / \mathrm{ml}$ sucrose solution. Scale bars $=$ $200 \mu \mathrm{m}$

Mutants had more necrotic tissue in leaves than did PI 114490 (Fig. 4f). These results indicated that SlPub24 contributed to resistance to race T3.

Spontaneous cell death in leaves was also observed in SlPub24-mutated plants that had not been inoculated with $X v 829$. Newly expanded leaves were normal, but areas of cell death were observed several days after expansion (Fig. 4g), and the leaves eventually became completely withered.

\section{Differential expression of SIPub24 in PI 114490 and OH} 88119 during disease development is caused by promoter sequence variation

Differential expression of SlPub24 was observed in PI 114490 and $\mathrm{OH} 88119$ during infection by $X$. euvesicatoria pv. perforans race T3 strain Xv829. In PI 114490, the expression of SlPub24 was at a constant low level from 0 to $96 \mathrm{hpi}$ and then dramatically increased, which was consistent with previous findings ${ }^{14,15}$. However, the expression of SlPub24 in $\mathrm{OH} 88119$ remained at a low level from 0 to 192 hpi (Fig. 5a).

To investigate why the expression of SlPub24 showed different patterns in PI 114490 and $\mathrm{OH}$ 88119, approximately $2.4 \mathrm{~kb}$ promoter sequences were obtained from the genomic DNA of these two lines. Substantial sequence variation in the promoter region of SlPub24 was observed between PI 114490 and $\mathrm{OH} 88119$. There were two large InDels, seven small InDels, and 16 SNPs between the two promoter sequences (Table S2). Both promoters were 
a

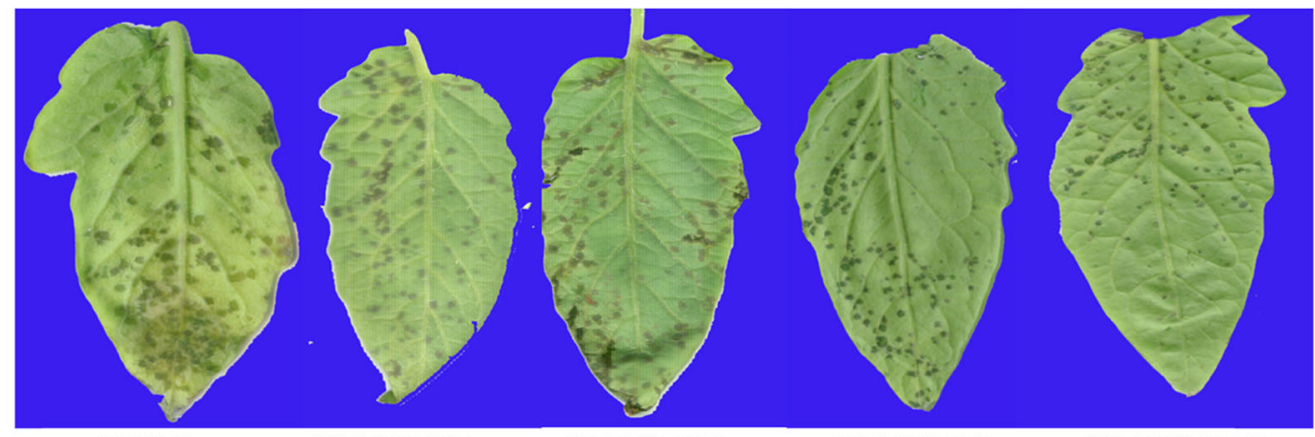

OH 88119 SIPub24PI-\#13-1

SIPub24PI-\#13-2

pSIPub24PI-\#342

pSIPub24PI-\#35-10

b

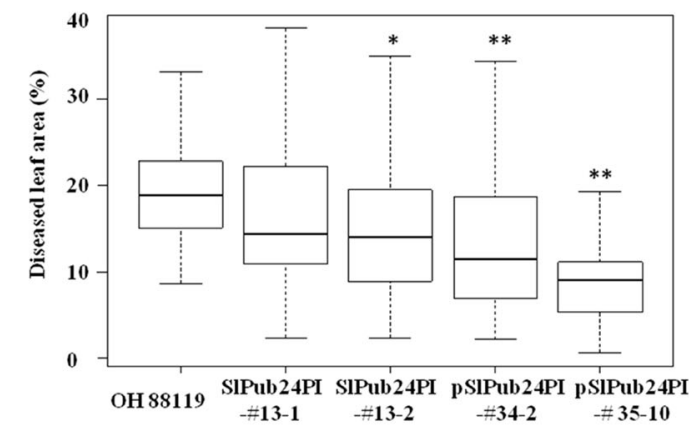

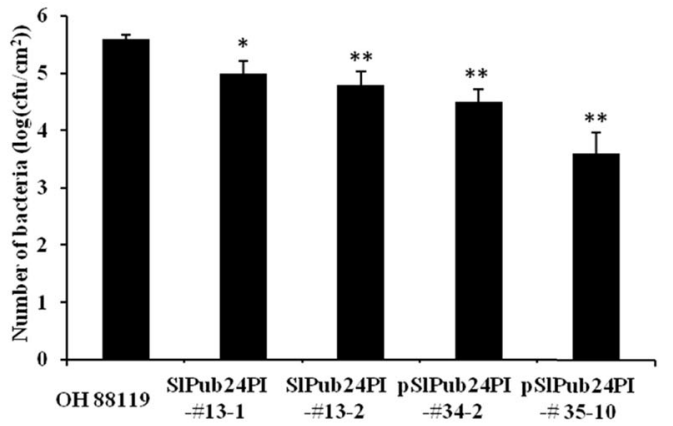

d
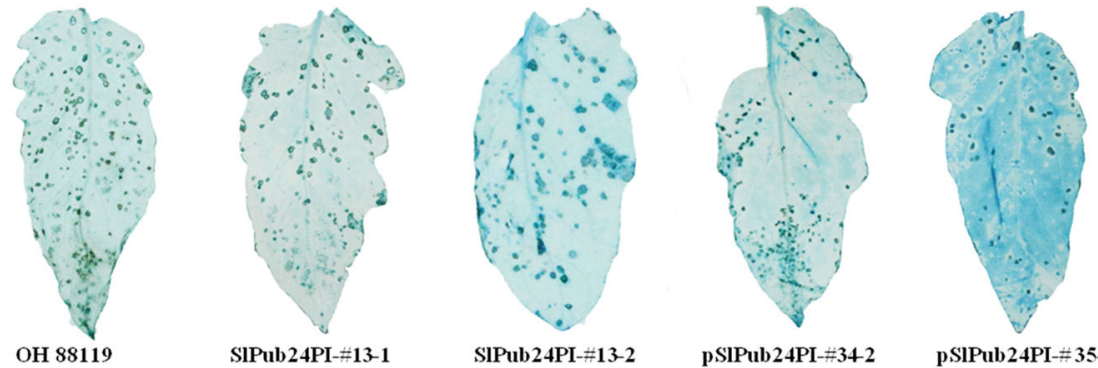

SIPub24PI-\#13-2

pSIPub24PI-\#34-2

pSIPub 24PI-\#35-10

Fig. 3 Transgenic overexpression of SIPub24 in the susceptible tomato line OH 88119 enhances resistance to Xanthomonas euvesicatoria pv. perforans race T3 strain Xv829. a Symptoms in leaves of OH 88119 and transgenic plants overexpressing SIPub24 isolated from PI 114490 at 7 days post inoculation (dpi). b Statistical analysis of disease in $\mathrm{OH} 88119$ and transgenic lines at 7 dpi. Error bars represent the SD $(n=30)$. c Bacterial populations in leaves of $\mathrm{OH} 88119$ and transgenic lines at 9 dpi. Error bars represent the SD $(n=30)$. $\mathbf{d}$ Trypan blue staining of diseased leaves of $\mathrm{OH}$ 88119 and transgenic lines $(n=30)$. The asterisks indicate statistical significance by $t$ test $\left({ }^{*} P<0.05,{ }^{*} P<0.01\right)$

separately fused with GUS (Fig. 5b) to determine their activities. The GUS activity assay in tobacco showed that the promoter activity of SlPub24 from OH 88119 was lower than that of SlPub24 from PI 114490 (Fig. 5c). GUS activity of the construct driven by the promoter isolated from PI 114490 was detected in leaves of $\mathrm{OH} 88119$ at $12 \mathrm{hpi}$ with $X \nu 829$, but no GUS activity of the construct driven by the promoter isolated from $\mathrm{OH} 88119$ was detected in leaves of PI 114490 (Fig. 5d). These results suggested that the sequence difference in the promoter region might cause a difference in the activities of the two promoters, resulting in different expression patterns of SlPub24 in response to infection with Xv829 in PI 114490 and OH 88119.
Further comparison of promoter activities was performed by switching the promoters and coding sequences (CDSs) of the SlPub24 gene originating from PI 114490 and $\mathrm{OH}$ 88119. Three constructs, pSIPub24PI::CDS-OH, pSlPub24OH::CDS-PI, and pSlPub24PI::CDS-PI (Fig. 5e), were developed to perform transient transformation experiments. The number of bacteria was significantly $(P$ $<0.05)$ lower when SlPub24 was driven by the promoter from PI 114490 than when it was driven by the promoter from $\mathrm{OH} 88119$ at $48 \mathrm{hpi}$ (Fig. 5f). These results suggested that the SlPub24 gene could confer resistance to $X$. euvesicatoria pv. perforans race T3 and that the differential expression of SlPub24 during pathogen infection in 
a

$$
\text { Target } 1 \text { Target } 2
$$$$
\operatorname{CDS}
$$$$
\text { TAG }
$$

b

$\begin{array}{llll}\text { Target1 } & \text { PAM } & \text { Target2 }\end{array}$

SIPub24PI(wild type): GATCCGGTAACGACGGT CACGGGGAT...GAGGTGGTGACCGCCACGTGCCCGG

SIPub24PI-Cri-53-1: GATCCGGTAACGACGGT CACGGGGAT...GAGGTGGTGACCGCCAC\# TGCCCGG

SIPub24PI-Cri-\#53-6: GATCCGGTAACGACGGT CACGGGGAT...GAGGTGGTGACCGCC\#\#\#\#\#\#CGG

SIPub24PI-Cri-\#54: GATCCGGTAACGA\#\#\#\# CACGGGGAT...GAGGT GGTGACCGCCACGTGCCCGG

SIPub24PI-Cri-\#45: GATCCGGTAACGACGGTTCACGGGGAT...GAGGTGGTGACCGCC\#\#\#\#\#\#CGG

C

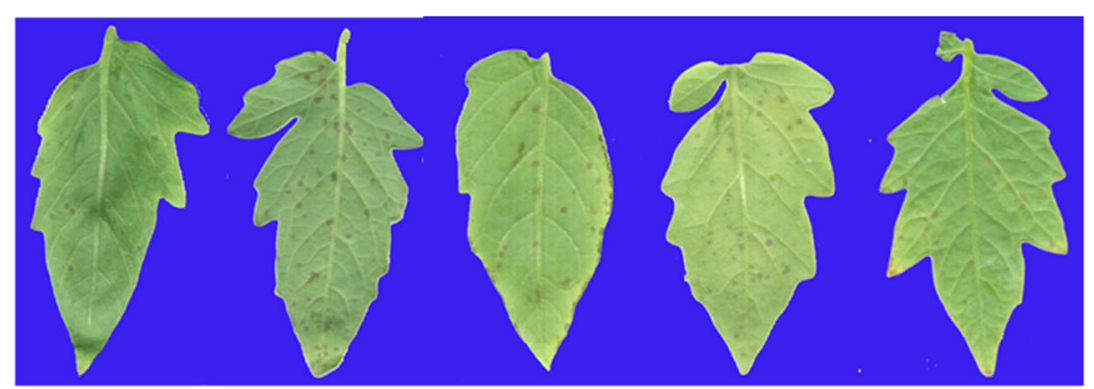

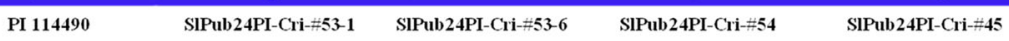

d
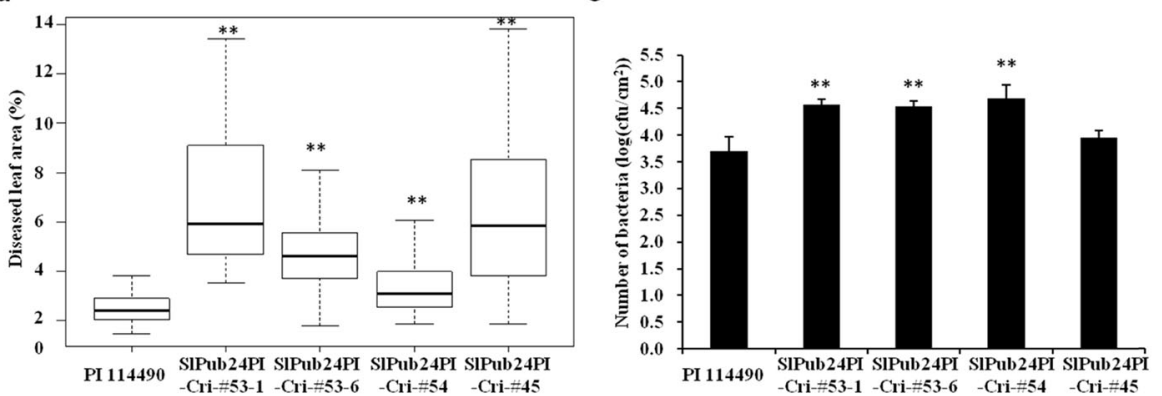

f

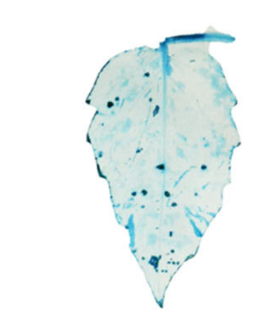

g
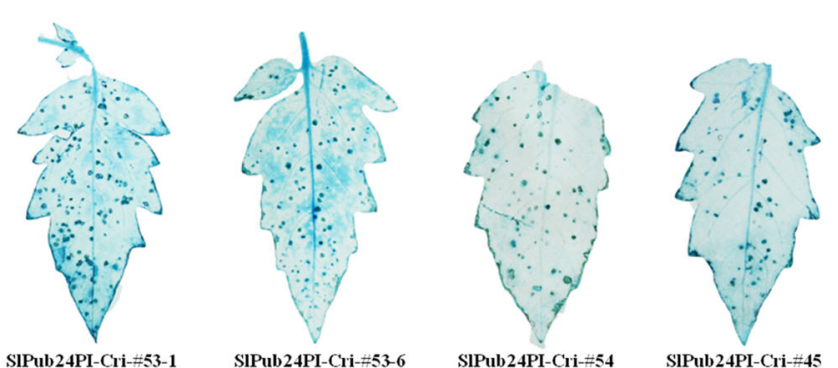

SIPub24PI-Cri-\#45

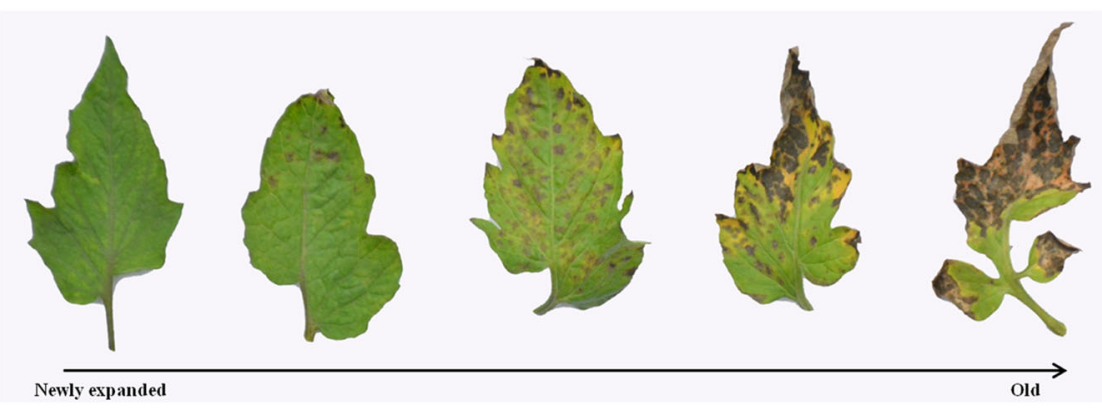

Fig. 4 (See legend on next page.) 
(see figure on previous page)

Fig. 4 Knockout of SIPub24 in the resistant line PI 114490 by the CRISPR/Cas9 editing system leads to decreased resistance to Xanthomonas euvesicatoria pv. perforans race T3 strain Xv829 and spontaneous cell death in leaves in mutants. a Schematic illustration of the two sgRNA target sites (red arrows) in SIPub24. b Mutations identified in four T2 mutant lines. Red font indicates protospacer-adjacent motif (PAM) sequences, and the sgRNA target sequence is underlined. c Symptoms on PI 114490 and mutant leaves at 7 days post inoculation (dpi). d Statistical analysis of disease in PI 114490 and mutants at 7 dpi. Error bars represent the SD $(n=30)$. e Bacterial population in leaves of PI 114490 and mutants at 9 dpi. Error bars represent the SD $(n=30)$. f Trypan blue staining of diseased PI 114490 and mutant leaves $(n=30)$. The asterisks indicate statistical significance by $t$ test $\left({ }^{* *} P<0.01\right)$. g Spontaneous cell death on leaves of mutants at various stages, from newly expanded to old leaves

PI 114490 and $\mathrm{OH} 88119$ might be due to sequence variation in the SlPub24 promoter region.

\section{SIPub24 is associated with resistance to race T3 in the} inbred backcross population derived from PI 114490 and other germplasms

The 6-bp InDel in the CDS between PI 114490 and $\mathrm{OH}$ 88119 was used as a marker (Table S1) to genotype individual lines of an inbred backcross (IBC) population derived from PI $114490^{8,12}$. The responses of each line in the IBC population to race $\mathrm{T} 3$ were the same as those in our previous publication ${ }^{12}$. Single marker-trait association analysis indicated that the marker was significantly ( $p=$ 0.0056) associated with resistance to race $\mathrm{T} 3$ in the population. The mean disease severity was 3.9 $(1-12 \text { scale })^{13}$ for lines carrying the PI 114490 allele and 6.4 for lines with the $\mathrm{OH} 9242$ or Fla 7600 allele. The marker explained $12.3 \%$ of the phenotypic variation in resistance to race $\mathrm{T} 3$ in the population.

Of the 192 tomato lines ${ }^{31}$ genotyped with markers to detect SlPub24 and Rx4, including PI 114490 and $\mathrm{OH}$ 88119,4 had only the SlPub24 gene, 3 had only the Rx4 gene, and 11 had both the SlPub24 and Rx4 genes (Table 1). Interestingly, nine lines showed evidence of chromosomal crossover events in this region. Seven lines had the PI 114490 marker genotype in the CDS and 5' UTR of SlPub24 but the OH 88119 marker genotype in the promoter region. Two near-isogenic lines (NILs) derived from Hawaii 7998, FG16-804 and FG16-813, had the same genotype as the donor. Line LA1269 had the $\mathrm{OH}$ 88119 marker genotype in the CDS but PI 114490 marker genotypes at the promoter and $5^{\prime} \mathrm{UTR}$ regions, while line LA1218 had the OH 88119 marker genotype in the CDS and $5^{\prime}$ UTR but the PI 114490 marker genotype at the promoter (Table 1). Twenty-six lines, including those with either the SlPub24 or Rx4 gene, 9 without both genes, and those with chromosomal crossovers, were subjected to disease evaluation by spray inoculation of race T3 strain $X v 829$. Lines carrying both the SlPub24 and Rx4 genes exhibited the lowest diseased leaf area (9.3\%), followed by lines carrying only $R x 4$ (11.0\%) from PI 128216 or SlPub24 (13.3\%) from PI 114490 (Table 1). Lines having chromosomal crossover without either the promoter or
CDS from PI 114490 exhibited the same level of susceptibility as lines without both SlPub24 and Rx4 genes. These data suggested that the promoter of SlPub24 from PI 114490 was critical for the function of SlPub24 in disease resistance and confirmed the results of switching the promoters and CDS of the SlPub24 gene originating from PI 114490 and $\mathrm{OH} 88119$.

\section{SIPub24 also confers resistance to races T1, T2, and T4}

Previous studies indicate that the locus QTL-11B from the resistant line PI 114490 confers resistance to races $\mathrm{T} 1-\mathrm{T} 4^{7,9}$. To check whether SlPub24 was also resistant to races T1, T2, and T4, PI 114490, OH 88119, and Slpub24 mutants and transgenic lines overexpressing SlPub24 were subjected to disease evaluation. Bacterial populations were significantly smaller in PI 114490 and transgenic lines than in $\mathrm{OH} 88119$ and Slpub24 mutants (Fig. S3), suggesting that SlPub24 also conferred resistance to races $\mathrm{T} 1, \mathrm{~T} 2$, and $\mathrm{T} 4$.

\section{Expression of SA-related genes and SA content are affected by SIPub24}

The expression of the SA synthesis-related gene phenylalanine ammonia-lyase $(P A L)$ and the signaling-related genes pathogenesis-related $(P R 1)$ and nonexpresser of $P R$ genes 1 (NPR1) in PI 114490, OH 88119, and transgenic plants was measured in this study. The expression levels of PAL, PR1, and NPR1 were low from 0 to 144 hpi and then dramatically increased from 144 to 192 hpi (Fig. 6a), similar to the expression pattern of SlPub24 in PI 114490 (Fig. 5a). However, they were expressed at very low levels in SlPub24mutated lines from 0 to $192 \mathrm{hpi}$ (Fig. 6a). In transgenic lines overexpressing SlPub24 isolated from PI 114490, the expression of PAL, PR1, and NPR1 was higher at 48, 192, and 72 hpi, respectively, than in $\mathrm{OH} 88119$ (Fig. 6b). The content of SA was consistent with the expression levels of SlPub24, PAL, PR1, and NPR1. The amount of SA in PI 114490 increased at 192 hpi but remained at a constant level in SlPub24-mutated lines (Fig. 6c). Meanwhile, the content of SA was higher in transgenic lines overexpressing SlPub24 than in $\mathrm{OH} 88119$ at 48 and 192 hpi (Fig. 6d). These results suggested that SIPUB24 might affect SA synthesis and signaling, which eventually influence resistance to bacterial spot. 
a

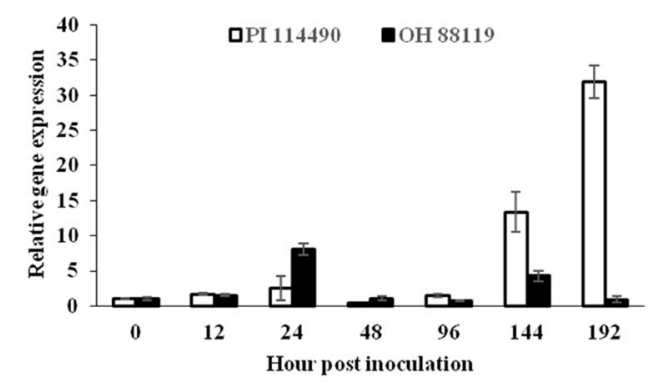

b

pCaMV35s::GUS

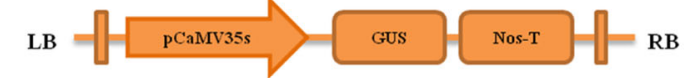

pSIPub24PI::GUS

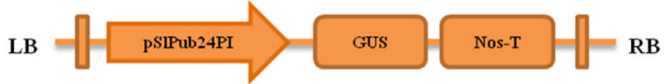

pSIPub24OH::GUS

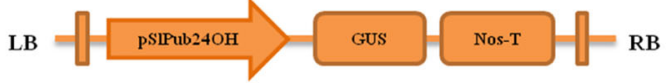

c

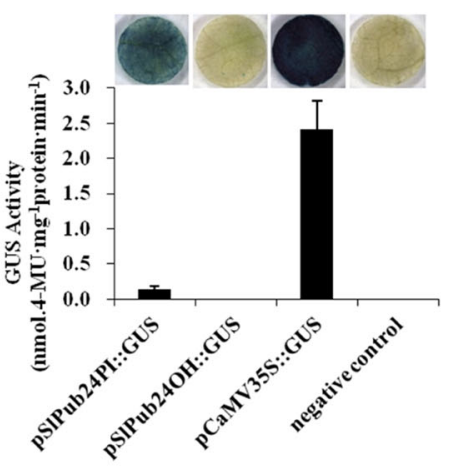

e

pSIPub24PI::CDS-OH

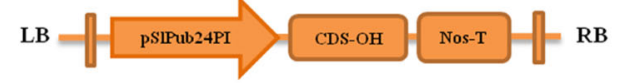

pSIPub24OH::CDS-PI

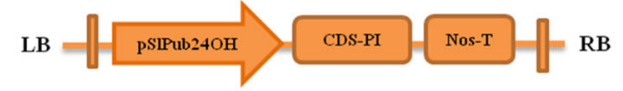

pSIPub24PI::CDS-PI

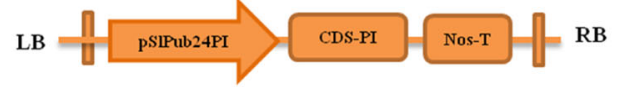

d

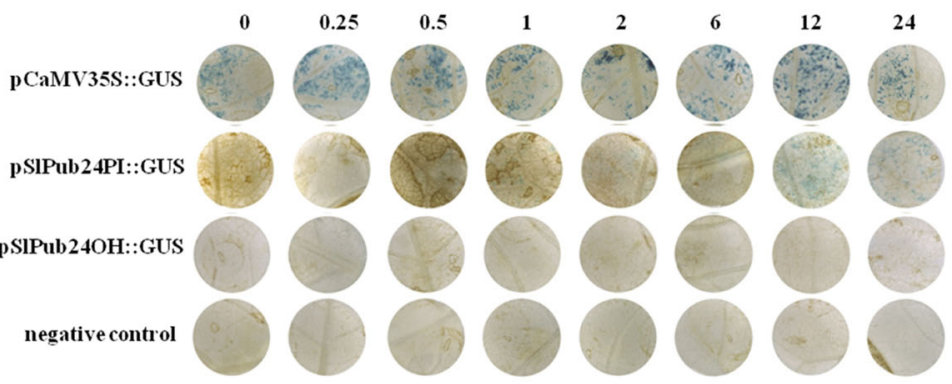

f

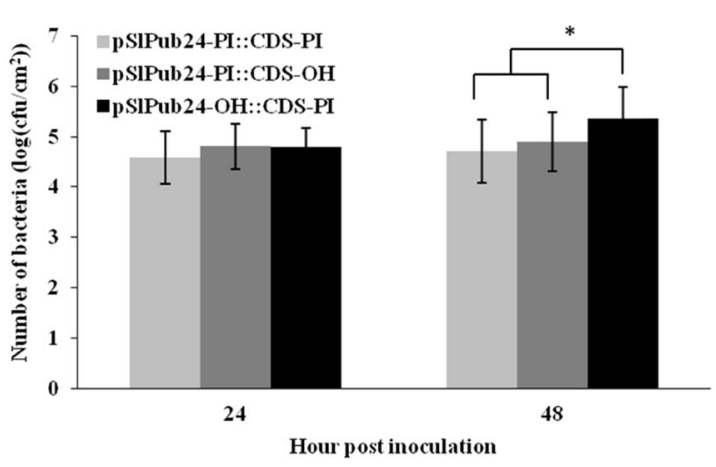

Fig. 5 Differential expression of SIPub24 in the resistant line PI 114490 and the susceptible line OH 88119 during infection by Xanthomonas euvesicatoria pv. perforans race T3 strain Xv829 is caused by sequence variation in the promoter. a Expression of SIPub24 in PI 114490 and $\mathrm{OH} 88119$ at various time points after spray inoculation with Xv829. b Schematic diagram of the vector construct. pSIPub24PI::GUS: The SIPub24 promoter isolated from PI 114490 was fused with the GUS reporter. pSIPub24OH::GUS: The SIPub24 promoter isolated from OH 88119 was fused with the GUS reporter. GUS $\beta$-glucuronidase, LB left border, NOS-T Nos terminator, RB right border. Agrobacterium tumefaciens GV3101 was used as a negative control, and pCaMV35S::GUS was used as a positive control. c GUS activity in leaves of Nicotiana benthamiana transiently expressing the pSIPub24PI::GUS or pSIPub24OH::GUS constructs. Error bars represent the SD $(n=6)$. $\mathbf{d}$ GUS activity in tomato leaves transiently expressing the PSIPUB24OH::GUS and pSIPUB24PI::GUS constructs at various hours after spray inoculation of Xv829. Agrobacterium strains carrying the constructs were infiltrated into tomato leaves at $48 \mathrm{~h}$ before inoculation with Xv829. e Schematic diagram of the vector construct. SIPub24PI::CDS-PI: the SIPup24 coding sequence (CDS) from PI 114490 driven by promoter from PI 114490; SIPub24PI::CDS-OH: the SIPub24 CDS from OH 88119 driven by promoter from PI 114490; SIPub24OH::CDS-PI: the SIPub24 CDS from PI 114490 driven by promoter from OH 88119 . $\mathbf{f}$ Bacterial population in leaves of OH 88119 plants transiently expressing constructs SIPub24PI::CDS-PI, SIPub24PI::CDS-OH, and SIPub24OH::CDS-PI. Error bars represent the SD $(n=6)$. The asterisks indicate statistical significance by $t$ test $\left({ }^{*} P<0.05\right)$

\section{SIPUB24 interacts with and promotes degradation of SICWP}

To gain insight into the regulation of SIPUB24, yeast two-hybrid ( $\mathrm{Y} 2 \mathrm{H})$ assays were performed to identify proteins that might interact with SIPUB24. After multiple screenings using deficient solid medium, 246 positive colonies associated with 55 genes were obtained, and 48 genes were finally obtained by PCR amplification. Constructs of 29 genes were successfully developed for interaction validation using the full-length CDS, and six genes (Table 2) showed interactions with SIPUB24 in three independent $\mathrm{Y} 2 \mathrm{H}$ experiments. One gene, Solyc02g085950 (designated SlCWP), represented by 21 colonies encoding the cell wall protein X77373, was 
Table 1 Marker genotype and response to Xanthomonas euvesicatoria pv. perforans race T3 strain Xv829 in tomato lines

\begin{tabular}{|c|c|c|c|c|c|}
\hline \multirow[t]{3}{*}{ Germplasm } & \multicolumn{4}{|l|}{ Marker genotype } & \multirow{3}{*}{$\begin{array}{l}\text { Mean diseased leaf } \\
\text { area }(\%)\end{array}$} \\
\hline & \multicolumn{3}{|l|}{ SIPub24 } & \multirow{2}{*}{$\begin{array}{l}R \times 4 \\
\text { 6-bp InDel in CDS }\end{array}$} & \\
\hline & $\begin{array}{l}\text { 284-bp InDel in } \\
\text { promoter }\end{array}$ & 198-bp InDel in 5'-UTR & 6-bp InDel in CDS & & \\
\hline Money maker & Slpub24SIpub24 & Slpub24SIpub24 & Slpub24SIpub24 & $r \times 4 r \times 4$ & $22.2 a$ \\
\hline Liger 87-05 & Slpub24SIpub24 & Slpub24SIpub24 & Slpub24SIpub24 & $r \times 4 r \times 4$ & \\
\hline Zhongshu 6 & Slpub24SIpub24 & Slpub24SIpub24 & Slpub24SIpub24 & $r \times 4 r \times 4$ & \\
\hline Hunt 100 & Slpub24SIpub24 & Slpub24SIpub24 & Slpub24SIpub24 & $r \times 4 r \times 4$ & \\
\hline Ailsa Craig & Slpub24SIpub24 & Slpub24SIpub24 & Slpub24SIpub24 & $r \times 4 r \times 4$ & \\
\hline Heinz 1350 & Slpub24SIpub24 & Slpub24SIpub24 & Slpub24SIpub24 & $r \times 4 r \times 4$ & \\
\hline Heinz 1706 & Slpub24SIpub24 & Slpub24SIpub24 & Slpub24SIpub24 & $r \times 4 r \times 4$ & \\
\hline $\mathrm{OH} 88119$ & Slpub24SIpub24 & Slpub24SIpub24 & Slpub24SIpub24 & $r \times 4 r \times 4$ & \\
\hline Rio Grande & Slpub24SIpub24 & Slpub24SIpub24 & Slpub24SIpub24 & $r \times 4 r \times 4$ & \\
\hline LA 1218 & SIPub24SIPub24 & Slpub24SIpub24 & Slpub24SIpub24 & $r \times 4 r \times 4$ & not included \\
\hline LA 1269 & SIPub24SIPub24 & SIPub24SIPub24 & Slpub24SIpub24 & $r \times 4 r \times 4$ & $22.2 a$ \\
\hline LA 2181 & Slpub24SIpub24 & SIPub24SIPub24 & SIPub24SIPub24 & $r \times 4 r \times 4$ & $21.2 \mathrm{a}$ \\
\hline LA 0395 & Slpub24SIpub24 & SIPub24SIPub24 & SIPub24SIPub24 & $r \times 4 r \times 4$ & \\
\hline Ha 7998 & Slpub24SIpub24 & SIPub24SIPub24 & SIPub24SIPub24 & $r \times 4 r \times 4$ & \\
\hline FG16-804 & Slpub24SIpub24 & SIPub24SIPub24 & SIPub24SIPub24 & $r \times 4 r \times 4$ & \\
\hline LA 2283 & Slpub24SIpub24 & SIPub24SIPub24 & SIPub24SIPub24 & $R \times 4 R \times 4$ & $15.6 a b$ \\
\hline Fla 8233 & Slpub24SIpub24 & SIPub24SIPub24 & SIPub24SIPub24 & $\mathrm{R} \times 4 \mathrm{R} \times 4$ & \\
\hline FG16-813 & Slpub24SIpub24 & SIPub24SIPub24 & SIPub24SIPub24 & $\mathrm{R} \times 4 \mathrm{R} \times 4$ & \\
\hline LA 0400 & Slpub24SIpub24 & SIPub24SIPub24 & SIPub24SIPub24 & $\mathrm{R} \times 4 \mathrm{R} \times 4$ & not included \\
\hline LA 2183 & Slpub24SIpub24 & SIPub24SIPub24 & SIPub24SIPub24 & $R \times 4 R \times 4$ & not included \\
\hline PI 114490 & SIPub24SIPub24 & SIPub24SIPub24 & SIPub24SIPub24 & $r \times 4 r \times 4$ & $13.3 b$ \\
\hline FG16-802 & SIPub24SIPub24 & SIPub24SIPub24 & SIPub24SIPub24 & $r \times 4 r \times 4$ & \\
\hline На 7981 & Slpub24SIpub24 & Slpub24SIpub24 & Slpub24SIpub24 & $\mathrm{R} \times 4 \mathrm{R} \times 4$ & $11.0 \mathrm{~b}$ \\
\hline TD-55C-h & Slpub24SIpub24 & Slpub24SIpub24 & Slpub24SIpub24 & $R \times 4 R \times 4$ & \\
\hline ZF084-1-h & Slpub24SIpub24 & Slpub24SIpub24 & Slpub24SIpub24 & $\mathrm{R} \times 4 \mathrm{R} \times 4$ & \\
\hline Black Cherry & SIPub24SIPub24 & SIPub24SIPub24 & SIPub24SIPub24 & $\mathrm{R} \times 4 \mathrm{R} \times 4$ & $9.3 b$ \\
\hline LA 0373 & SIPub24SIPub24 & SIPub24SIPub24 & SIPub24SIPub24 & $\mathrm{R} \times 4 \mathrm{R} \times 4$ & \\
\hline PI 128216 & SIPub24SIPub24 & SIPub24SIPub24 & SIPub24SIPub24 & $\mathrm{R} \times 4 \mathrm{R} \times 4$ & \\
\hline Nongdazhenzhufanqie & SIPub24SIPub24 & SIPub24SIPub24 & SIPub24SIPub24 & $\mathrm{R} \times 4 \mathrm{R} \times 4$ & \\
\hline LA 0722 & SIPub24SIPub24 & SIPub24SIPub24 & SIPub24SIPub24 & $\mathrm{R} \times 4 \mathrm{R} \times 4$ & not included \\
\hline 11C336 & SIPub24SIPub24 & SIPub24SIPub24 & SIPub24SIPub24 & $\mathrm{R} \times 4 \mathrm{R} \times 4$ & not included \\
\hline 11C337 & SIPub24SIPub24 & SIPub24SIPub24 & SIPub24SIPub24 & $\mathrm{R} \times 4 \mathrm{R} \times 4$ & not included \\
\hline
\end{tabular}

Tomato germplasms with fewer than three plants available for disease evaluation were not included in the least significant difference comparison. Means of diseased leaf area followed by the same letter are not significantly different at $P \leq 0.05$ based on Duncan's multiple range test 
a
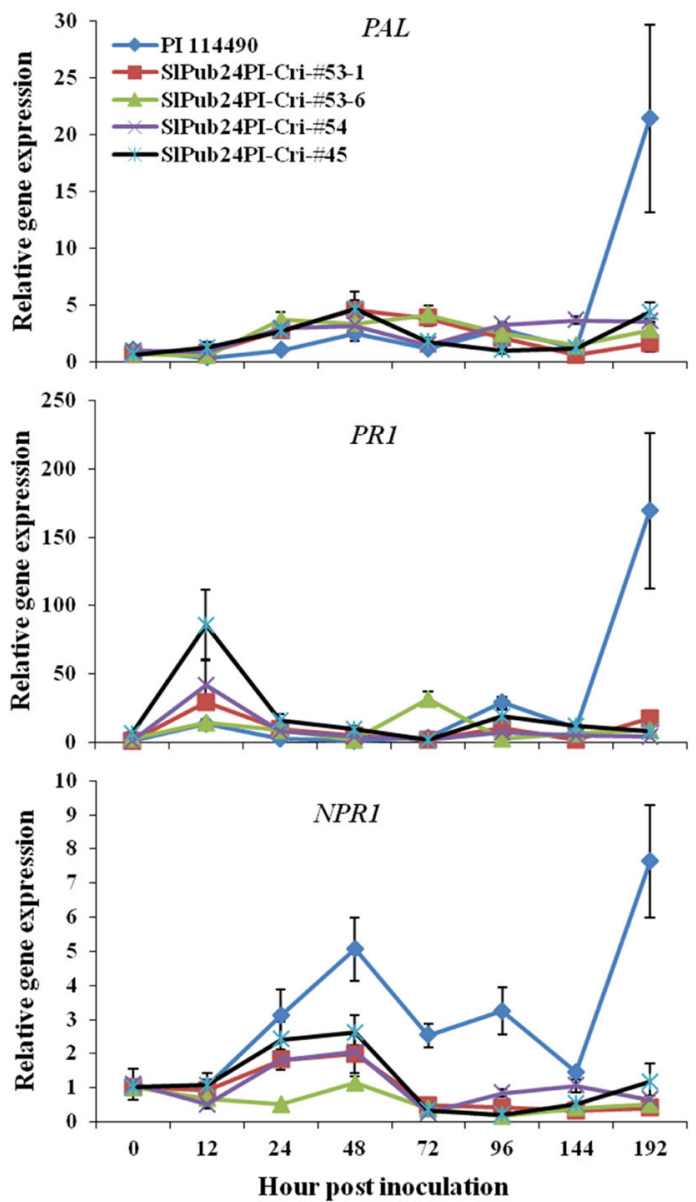

C

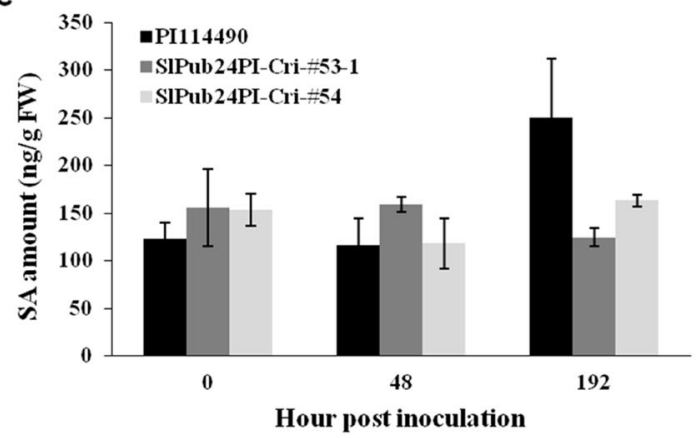

b
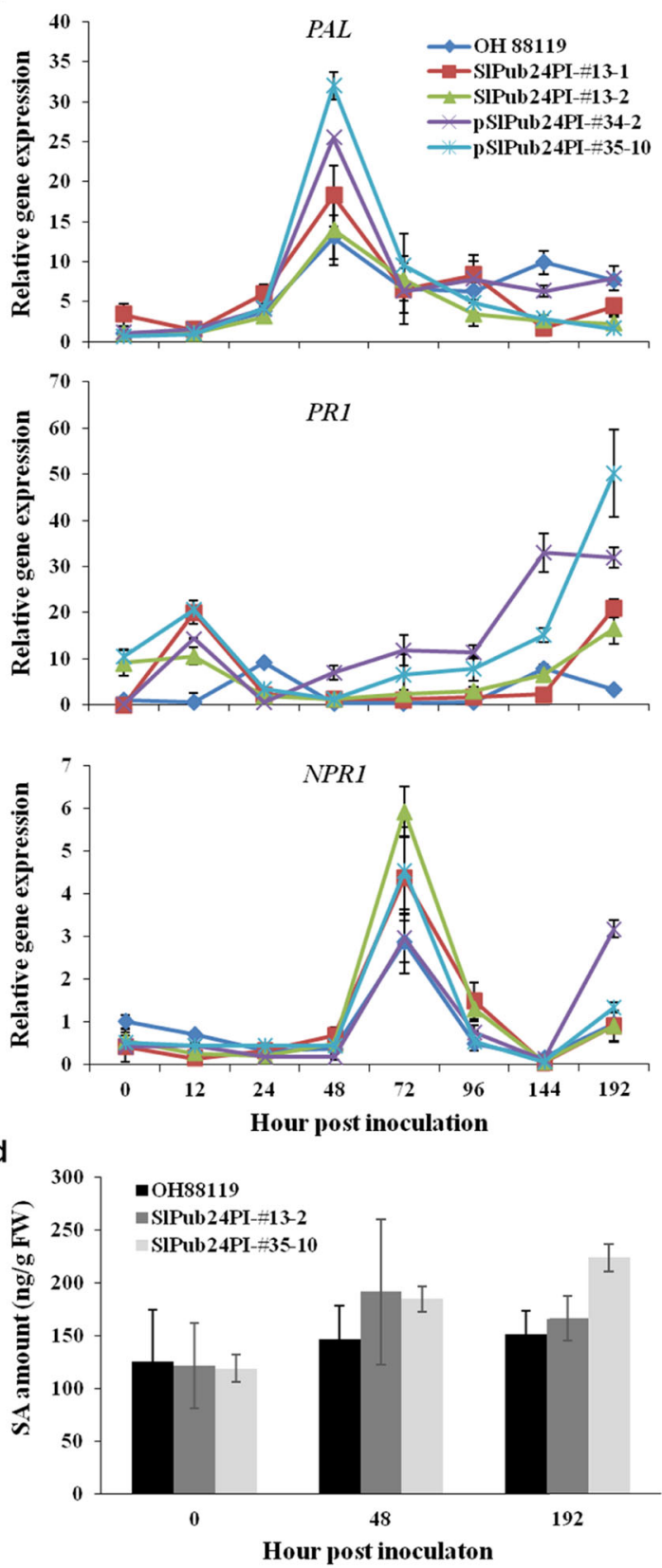

Fig. 6 Relative expression of salicylic acid (SA)-related genes and accumulation of SA in tomato lines at various time points after spray inoculation of Xanthomonas euvesicatoria pv. perforans race T3 strain Xv829. a Relative expression of PAL, PR1, and NPR1 in the resistant tomato line PI 114490 and SIPub24-mutated lines. b Relative expression of PAL, PR1, and NPR1 in the susceptible tomato line OH 88119 and transgenic lines overexpressing SIPub24 isolated from PI 114490. c SA content in PI 114490 and SIPub24-mutated lines at 0, 48, and $192 \mathrm{~h}$ post inoculation (hpi) with XV829. d SA content in OH 88119 and transgenic lines overexpressing SIPub24 at 0, 48, and $192 \mathrm{hpi}$ of Xv829. PAL phenylalanine ammonia-lyase gene, PR1 pathogenesis-related gene 1, NPR1 nonexpresser of PR gene 1. Error bars represent the SD $(n=3)$

selected for further investigation because it has been reported that cell wall proteins participate in disease defense $^{32}$. The interaction between SIPUB24 and SICWP detected by $\mathrm{Y} 2 \mathrm{H}$ (Fig. 7a) was verified by bimolecular fluorescence complementation assay (BiFC) and split luciferase complementation assay (SLC) (Fig. 7b, c).

A previous study showed that proteins containing the U-box domain have ubiquitin ligase E3 activity that leads 
to protein degradation by the $26 \mathrm{~S}$ proteasome. MG-132 is a cell-permeable proteasome inhibitor and can block the proteolytic activity of the $26 \mathrm{~S}$ proteasome complex ${ }^{33}$. To further prove the relationship between SIPUB24 and SICWP, SIPUB24-Myc and SICWP-Flag were cloned into the vector, and an Agrobacterium-mediated transient expression assay was implemented in $N$. benthamiana

Table 2 Information on proteins interacting with SIPUB24 in tomato.

\begin{tabular}{ll}
\hline Gene ID & Function annotation \\
\hline Solyc12g005630 & Cytochrome b6-f complex iron-sulfur subunit \\
Solyc03g034220 & Ribulose bisphosphate carboxylase small chain 2B \\
Solyc02g085950 & Cell wall protein X77373 \\
Solyc08g028690 & NAD(P)-binding Rossmann-fold superfamily protein \\
Solyc02g094120 & Sulfite oxidase \\
Solyc06g071050 & Hypersensitive-induced response protein \\
\hline
\end{tabular}

leaves. Immunoblot analysis indicated that SICWP gradually accumulated and was not degraded by SIPUB24 in tobacco leaves treated with MG132 (Fig. 7d), which indicated that SIPUB24 might promote the degradation of SlCWP.

\section{The expression of SICWP is opposite to that of SICWIINV1} during the infection of $X$. euvesicatoria pv. perforans race T3

The relative expression of SlCWP in PI 114490 was significantly lower at $192 \mathrm{hpi}$ than at $0 \mathrm{hpi}$ of $X \nu 829$ (Fig. 8a). However, its expression was significantly upregulated at 192 hpi in CRISPR/Cas9-generated mutants of SlPub24 (Fig. 8b). Previous studies have shown that increased invertase activity can enhance the levels of factors (cellulose, xylose, and galactose) involved in cell wall reinforcement $^{34}$. The bacterium $X v 829$ can grow in leaves of PI 114490, but no or fewer symptoms occur on the leaf surface of these plants compared to plants of the susceptible line $\mathrm{OH} 88119^{12}$ and bacterial propagation only happens below the epidermal cells in leaves of PI
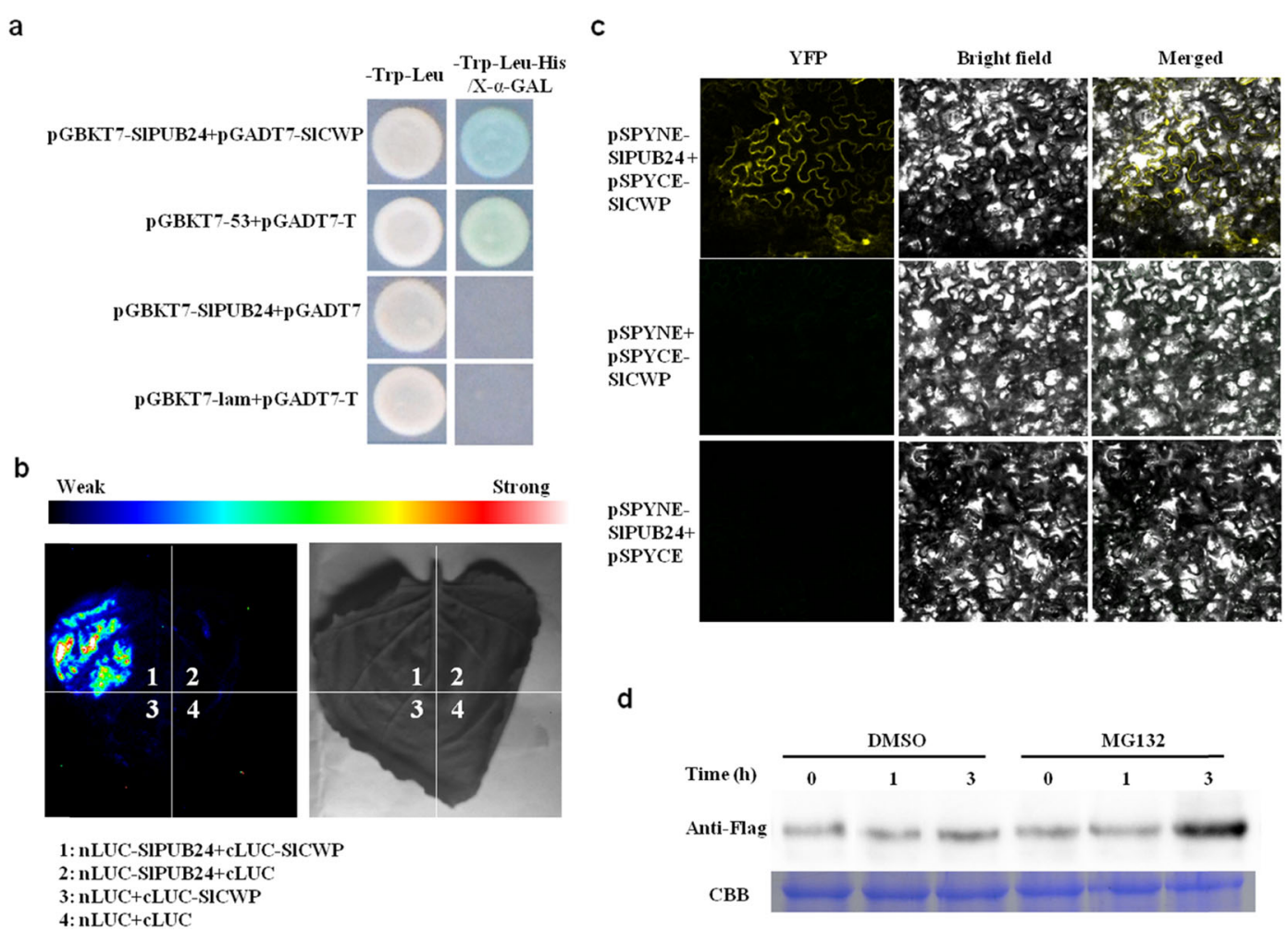

d

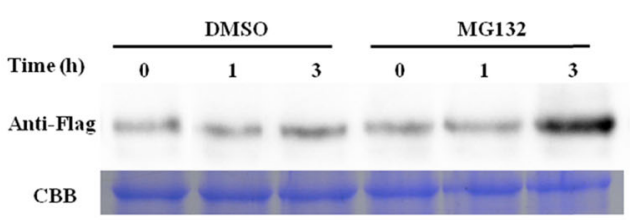

Fig. 7 SIPUB24 interacts with SICWP and regulates the degradation of SICWP. a Yeast-two-hybrid assay. The interactions between pGADT7 and pGBKT7-SIPUB24 and between pGADT7-T and pGBKT7-lam were used as negative controls, and the interaction between pGADT7-T and pGBKT7-53 was used as a positive control. $\mathbf{b}$ Luciferase complementation image assay. Fluorescence signal intensity represents the interaction of the two proteins. c Bimolecular fluorescence complementation assay. YFP fluorescence was detected by confocal microscope. $\mathbf{d}$ The protein levels of SICWPFlag in tobacco leaves at 0,1 , and $3 \mathrm{~h}$ after treatment with the proteasomal inhibitor MG132 (50 mM) or an equivalent volume of dimethylsulfoxide (DMSO, control) were determined by immunoblot analysis with the Flag antibody. The concentration of total protein was monitored by Coomassie brilliant blue (CBB) staining. Molecular weight of protein: SICWP $=20.22 \mathrm{kDa}$ 
a

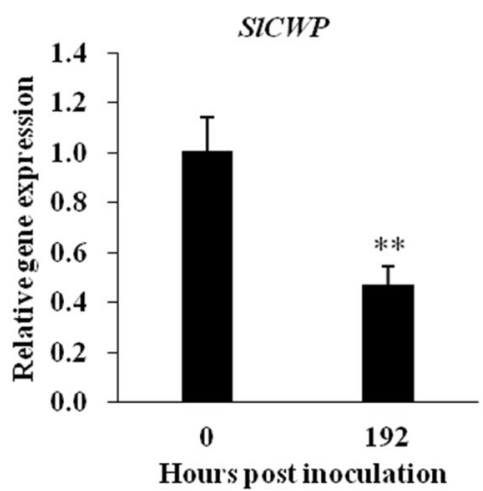

C

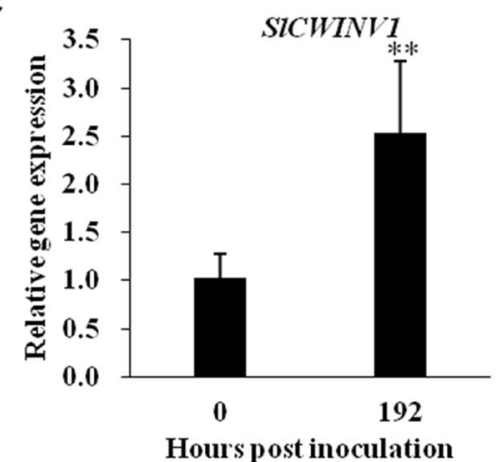

e

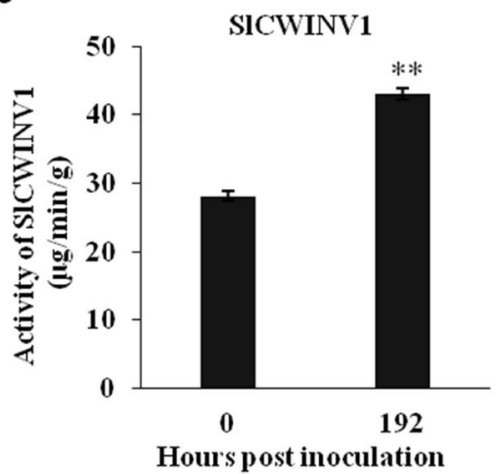

b

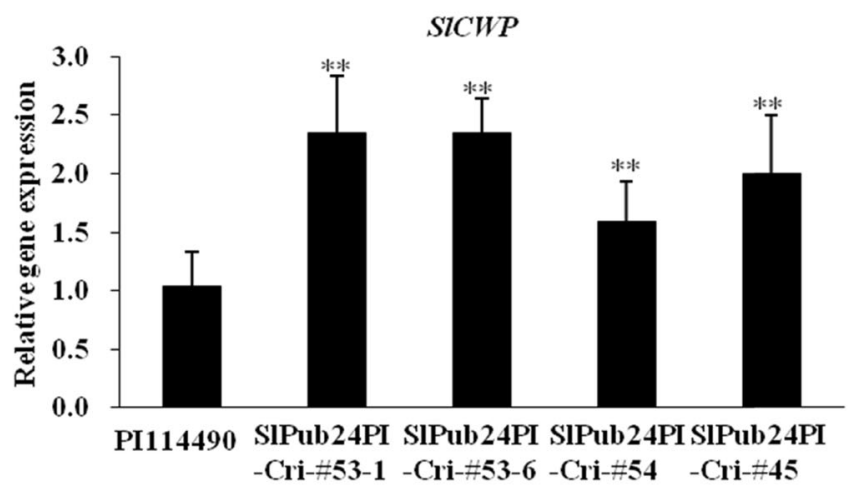

d
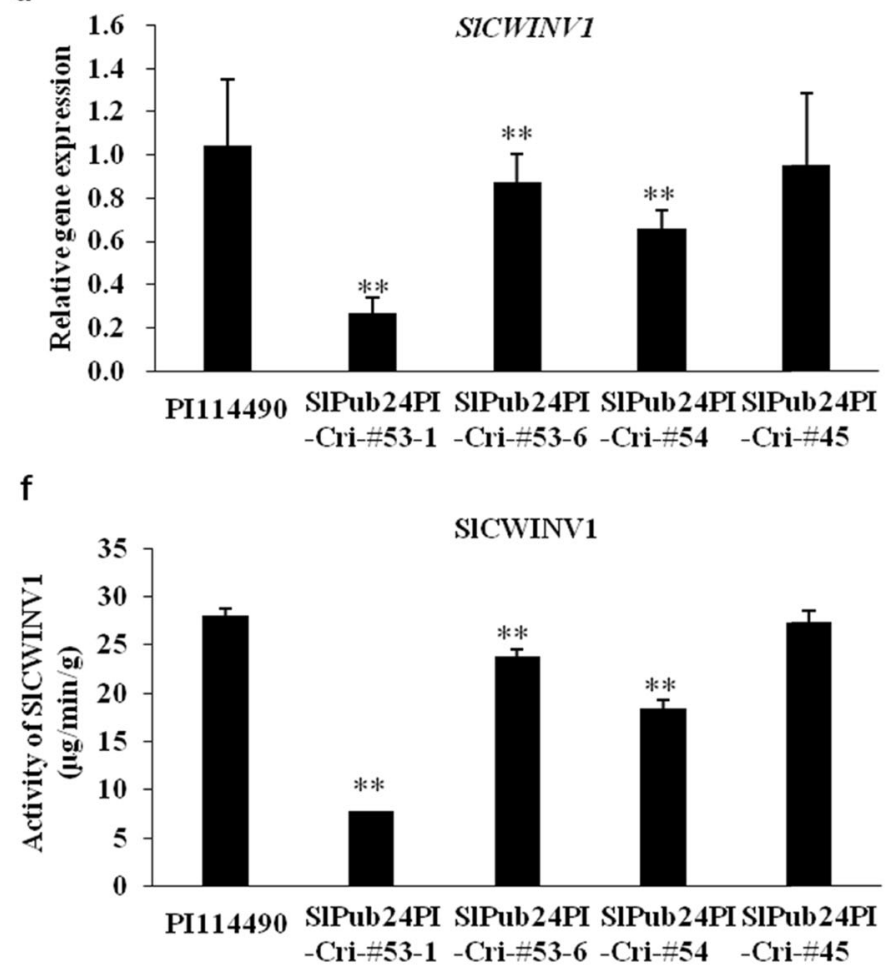

Fig. 8 Relative expression of SICWP and SICWINV1 as well as enzyme activity of SICWINV1 in leaves of plants after inoculation with Xanthomonas euvesicatoria pv. perforans race T3 strain Xv829. a Relative expression of SICWP in PI 114490 at 0 and $192 \mathrm{~h}$ post inoculation (hpi). b Relative expression of SICWP in PI 114490 and SIpub24 mutants generated by CRISPR/Cas9 editing at 192 hpi. c Relative expression of SICWINV1 in PI 114490 at 0 and 192 hpi. d Relative expression of SICWINV1 in PI 114490 and Slpub24 mutants generated by CRISPR/Cas9 editing at 192 hpi. e Activity of SICWINV1 in PI 114490 at 0 and 192 hpi. f Activity of SICWINV1 in PI 114490 and Slpub24 mutants generated by CRISPR/Cas9 editing at 192 hpi. Error bars represent the SD $(n=3)$

$114490^{35}$, suggesting that cell wall defense response might be distinct between resistant and susceptible tomato lines ${ }^{35}$. Therefore, the expression of the SlCWINV1 (Solyc03g121680) gene encoding the cell wall invertase was examined here. The data showed that the expression of SlCWINV1 was opposite to that of SlCWP. The relative expression of SlCWINV1 in PI 114490 was significantly higher at $192 \mathrm{hpi}$ than at 0 hpi for $X v 829$
(Fig. 8c), while the gene was downregulated in the mutants (Fig. 8d). SlCWINV1 activity was consistent with gene expression. The activity of SlCWINV1 in PI 114490 was significantly higher at $192 \mathrm{hpi}$ than at $0 \mathrm{hpi}$ (Fig. 8e), whereas the activity of SlCWINV1 was significantly lower in the three mutants, SIPub24PI-Cri\#531, SlPub24PI-Cri\#53-6, and SlPub24PI-Cri\#54, than in PI 114490 (Fig. 8f). 


\section{Discussion}

As a tomato source with broad-spectrum resistance to bacterial spot, PI 114490 has been used in various breeding programs to develop new lines with partial resistance to different species and races of Xanthomonas ${ }^{8-10,36}$. Several studies have shown that the common locus QTL-11b on chromosome 11 is responsible for the resistance to multiple species and races of Xanthomo$n a s^{7,9,10,12,13}$. The phenotypic variation explained by the locus varies from 12.5 to $29.4 \%$ depending on the population of plants and the species of the pathogen used for genetic analyses $^{10,12,13}$. Based on linkage map position ${ }^{12}$ and transcriptome data ${ }^{14,15}$, SlPub24 was identified as a strong candidate gene in the locus for resistance to race T3, and SlPub24 was further investigated in this study. Transgenic overexpression of SlPub24 in the susceptible line $\mathrm{OH} 88119$ increased resistance to race T3 (Fig. 3), while mutation of the gene in the resistant line PI 114490 using the CRISPR/Cas9 editing system decreased resistance to race T3 in mutants (Fig. 4). Furthermore, disease evaluation of mutants and transgenic lines showed that SlPub24 also conferred resistance to races T1, T2, and T4 (Fig. S3). These results suggest that SlPub24 is the gene for resistance to races $\mathrm{T} 1-\mathrm{T} 4$ in the locus $Q T L-11 B$.

Gene expression is largely dependent on its promoter activity. Sequence variation in the promoter region, including nucleotide substitution and insertion/deletion of certain fragments, can affect the timing and level of gene expression. Low expression of fw 2.2 in tomato plants with large fruits is due to one or more nucleotide substitutions in the promoter region of the gene ${ }^{37,38}$. The presence of an 11-bp InDel in the promoter region of the SD1 gene disrupts a gibberellin-responsive cis-element, resulting in low expression of the gene in thin-stem tomato plants ${ }^{39}$. Similarly, insertion of an 11-bp fragment in the promoter region of the $B s 3$ gene results in the loss of specific recognition by AvrBs3 from the pepper bacterial spot pathogen $X$. euvesicatoria pv. euvesicatoria ${ }^{40,41}$, while a deletion of $3 \mathrm{bp}$ in the promoter region of the $\mathrm{Xa27}$ gene causes the loss of specific recognition by AvrXa27 of the rice bacterial blight pathogen X. oryzae $p v$. oryzae $^{42}$. In the current study, substantial sequence variation was detected in the promoter regions of SlPub24 between PI 114490 and $\mathrm{OH} 88119$ (Table S2). Promoter activity analysis (Fig. 5c, d) indicated that the promoter of SlPub24 in $\mathrm{OH} 88119$ might have very low activity. Thus, the expression of the gene was low in $\mathrm{OH} 88119$ regardless of whether there was pathogen infection (Fig. $5 \mathrm{a})$. The results of swapping the promoter and CDS regions isolated from $\mathrm{PI} 114490$ and $\mathrm{OH} 88119$ indicated that the CDS of SlPub24 from both PI 114490 and $\mathrm{OH}$ 88119 could contribute to resistance to race T3 (Fig. 5f), although sequence variation in the CDS of SlPub24 existed between the two tomato lines. All these data suggested that the expression level of $S l P u b 24$ was determined by the activity of its promoter.

Salicylic acid is an important signaling molecule that induces systemic acquired resistance and is associated with pathogen resistance in plants ${ }^{43,44}$. It has been shown that plants generate SA via the Phenylalanine AmmoniaLyase (PAL) pathway ${ }^{45-48}$, and the relative expression of pathogenesis-related $(P R)$ genes and nonexpresser of $\mathrm{PR}$ genes 1 (NPR1) are reliable indicators of the activity of SA signaling ${ }^{49}$. The expression of $P A L$ influences the accumulation of pathogen-induced SA and is associated with disease resistance ${ }^{50,51}$. Various studies have shown that plant U-box proteins regulate disease resistance through the SA signaling pathway. Overexpression of CMPG1-V, which encodes a U-box E3 ubiquitin ligase in wheat, can improve broad-spectrum resistance to powdery mildew via increased expression of SA-responsive genes ${ }^{26}$. Overexpression of OsPUB15 in rice causes increased expression of $P R$ genes and enhanced resistance to blast strains in transgenic lines ${ }^{52}$. Knockdown of OsPUB44 through RNAi significantly suppresses the expression of PAL1 and decreases resistance to Xanthomonas oryzae pv. oryzae in transgenic rice lines ${ }^{53}$. In this study, the relative expression of the $P R 1, P A L$, and NPR1 genes increased in PI 114490 when plants were infected by race T3 strain Xv829 but remained at a low level in lines with SlPub24 mutated by CRISPR/Cas9 editing (Fig. 6a). In contrast, the transcription of these three genes was lower in $\mathrm{OH} 88119$ than in the transgenic lines overexpressing SlPub24 (Fig. 6b). It should also be noted that the increase in $P R 1, P A L$, and NPR1 expression (Fig. 6a) occurred later than the increase in SlPub24 expression (Fig. 5a) in PI 114490. The SA content in tomato plants was consistent with the expression levels of SlPub24, PAL, PR1, and NPR1 (Fig. 6c, d). These data suggested that SIPUB24 conferred resistance to bacterial spot by regulating the biosynthesis and signaling of SA.

The plant cell wall is the first barrier to pathogen infection, as it can prevent pathogens from entering the cells. It is also the matrix for many proteins involved in pathogen perception. By destroying the cell wall, the pathogen exposes the cell to itself, causing a series of innate immune reactions in plants ${ }^{32}$. Cell wall invertase (CWI) responds to wounding and pathogen infections. Elevated CWI activity induces resistance to Pseudomonas syringae pv. tomato DC3000 in melatonin-treated Arabidopsis $^{34}$. CWI can be regulated by specific invertase inhibitor proteins, such as cell wall/vacuolar invertase inhibitors (C/VIFs). AtC/VIF1 showed specific inhibition of VI activity, but AtC/VIF2 inhibited CWI and $\mathrm{VI}^{54}$. A previous study showed that bacteria can enter and propagate in the leaves of PI 114490 plants but are restricted to spongy cell layers due to the formation of wall appositions at the junction between adjacent mesophyll cells ${ }^{35}$. 


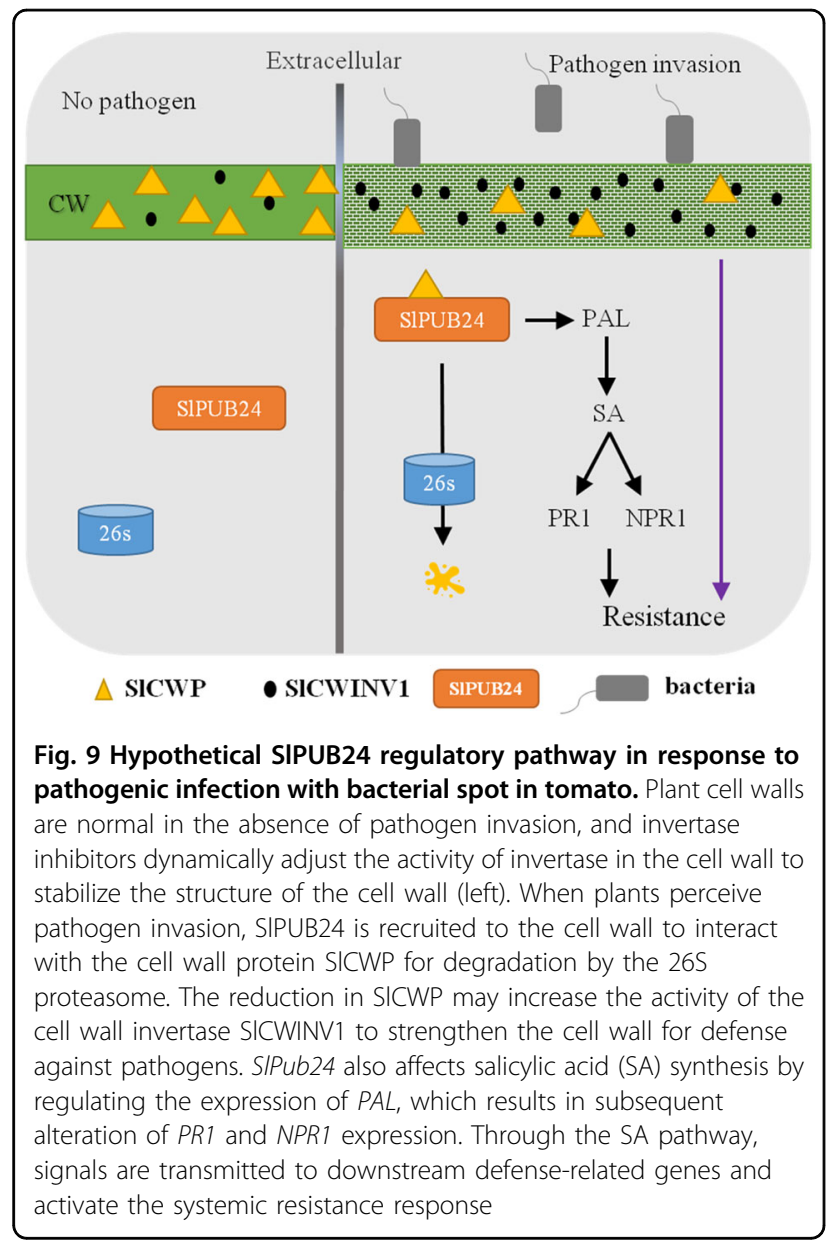

Thus, the cell wall of PI 114490 might function to prohibit bacterial migration. In this study, the interaction of the cell wall protein SICWP with SIPUB24 was identified through $\mathrm{Y} 2 \mathrm{H}$ and verified by BiFC and SLC (Fig. 7). The expression of SlCWP and SlCWINV1 showed the opposite patterns (Fig. 8), suggesting that SlCWP might inhibit the expression of SlCWINV1 during pathogen infection. However, the expression of SlCWP showed the same pattern as SlPub24. Therefore, it was most likely that SIPUB24 recruited and degraded SICWP during pathogen infection, removing the inhibition of SICWP on SlCWINV1. SlCWINV1 plays a role in cell wall reinforcement to form wall appositions to prevent bacterial migration (Fig. 9). Meanwhile, SlPub24 affected the expression of $P A L$, resulting in changes in SA content and subsequently influencing the expression of $P R 1$ and $N P R 1$, which eventually activated plant resistance.

\section{Materials and methods Plant materials}

Solanum lycopersicum var. cerasiforme accession PI 114490 with field resistance ${ }^{8,12}$ and S. lycopersicum variety $\mathrm{OH} 88119$ without resistance to Xanthomonas euvesicatoria pv. perforans race $\mathrm{T} 3^{4,6}$ were used for gene isolation, gene expression, and genetic transformation. Nicotiana benthamiana plants were used for Agrobacterium-mediated transient expression analysis. A germplasm collection consisting of 192 tomato lines ${ }^{31}$ and three near-isogenic lines (NILs), FG16-802 carrying the SlPub24 gene from PI 114490, FG16-804 carrying a QTL on chromosome 11 from Hawaii 7998, and FG18-813 carrying the QTL from Hawaii 7998 and the Rx4 gene from PI 128216, was subjected to genotyping with the marker for selection of the SlPub24 gene, and 26 (Table 1) were selected for disease evaluation. The NILs with partial field resistance to race T3 were kindly provided by Dr. David M. Francis at The Ohio State University. All plants were grown in greenhouses with water and fertilizer supplied unless otherwise described.

\section{Molecular cloning and bioinformatic analysis of SIPub24 and SICWP}

Based on previous map position ${ }^{12}$ and transcriptome data $^{14}$, SlPub24 was selected as a candidate gene for the locus $Q T L-11 B$ on chromosome 11 conferring resistance to race T3. The full-length cDNAs and promoters were amplified from PI 114490 and $\mathrm{OH} 88119$ using genespecific primers (Table S1). The open reading frame was predicted using ORFfinder in NCBI (https://www.ncbi. nlm.nih.gov/orffinder/). Alignment of deduced amino acid sequences between PI 114490 and $\mathrm{OH} 88119$ was performed using Clustal X (http://www.clustal.org/). Functional domains were predicted using the SMART online tool (http://smart.embl-heidelberg.de/), and phylogenetic trees were created by MEGA $\mathrm{X}^{55}$ using the neighbor-joining method with 1000 bootstrap replicates. Bootstrap values are shown as percentages.

\section{RNA isolation and quantitative RT-PCR analysis}

Total RNA was isolated from tomato leaves using the Quick RNA Isolation Kit (Huayueyang Biotechnology Co., Beijing, China) following the manufacturer's instructions. The concentration of total RNA was determined using a NanoDrop 2000 Spectrophotometer (Thermo Fisher Scientific, Delaware, USA). Single-stranded cDNA was synthesized using the Prime Script ${ }^{\mathrm{TM}}$ RT reagent Kit with gDNA Eraser (Takara Bio Inc., Dalian, China) following the manufacturer's instructions. Quantitative RT-PCR was performed in a 10- $\mu \mathrm{l}$ reaction volume containing $1 \mu \mathrm{l}$ of diluted cDNA, $5 \mu \mathrm{TB}$ Green $^{\mathrm{TM}}$ Premix Ex Taq ${ }^{\mathrm{TM}}$ (Tli RNaseH Plus) (TaKaRa), $0.25 \mu$ l ROX Reference Dye (50x), $0.25 \mu \mathrm{l}$ each of forward and reverse gene-specific primers (Table S1), and $3.25 \mu \mathrm{l}$ sterile purified water. The tomato EF1-a (Solyc06g005060) or actin (Solyc11g005330) gene was used as an internal reference gene ${ }^{15,56}$. Relative expression values were determined using the comparative Ct method $\left(2^{-\Delta \Delta C t}\right)^{57}$. 


\section{Determination of SIPub24 promoter activity}

Measurement of promoter activity was performed by GUS assay. Promoters of the SlPub24 gene amplified from genomic DNA of PI 114490 and $\mathrm{OH} 88119$ were separately fused with the GUS reporter and cloned into the pCAMBIA1305.1 vector. The resulting constructs were transiently expressed in $N$. benthamiana leaves using the Agrobacterium-mediated transfection method. A. tumefaciens GV3101 and pCaMV35S::GUS were used as negative and positive controls, respectively. The infiltrated leaves were harvested 3 days after infiltration. Leaf discs ( $5 \mathrm{~mm}$ in diameter) were histochemically stained with 5bromo-4-chloro-3-indolyl b-D-glucuronide (X-Gluc) for $24 \mathrm{~h}$ at $37^{\circ} \mathrm{C}$ and then incubated in $70 \%$ ethanol for $48 \mathrm{~h}$ to remove chlorophyll before photographing. For measurements of GUS activity, 4-methylumbelliferyl beta-Dglucuronide (4-MUG, Sigma-Aldrich, USA) was added as a substrate for the fluorometric assay using the method previously described ${ }^{58}$, and the 4-MU produced in the GUS reaction was measured by a Thermo Scientific Microplate Reader (Thermo Fisher Scientific, DE, USA). The concentration of total protein extracted from the leaf discs was measured using a Micro BCA Protein Assay Kit (CoWin Biotech Co. Ltd., Jiangsu, China). Final GUS activity was calculated according to the standard curve of 4-MU (Sigma Aldrich) and expressed as nmol.4-MU $\mathrm{mg}^{-1}$ protein $\mathrm{min}^{-1}$.

To compare the promoter activities of the SlPub24 gene during bacterial infection in PI 114490 and $\mathrm{OH}$ 88119, the expression of the GUS reporter driven by the $2.4 \mathrm{~kb}$ promoter isolated from PI 114490 in $\mathrm{OH} 88119$ plants and driven by the $2.4 \mathrm{~kb}$ promoter isolated from $\mathrm{OH}$ 88119 in PI 114490 plants was measured at $0,0.25,0.5,1$, $2,6,12$, and 24 h post inoculation (hpi) of $X$. euvesicatoria pv. perforans race T3 strain $X v 829$. The promoter of CaMV35S fused with the GUS reporter was cloned into pCAMBIA1305.1 and used as the positive control, while A. tumefaciens GV3101 was used as the negative control. The specific primers for amplification of promoters are listed in Table S1.

\section{Overexpression of SIPub24 in the susceptible line $\mathrm{OH}$ 88119}

Overexpression of SlPub24 isolated from the resistant line PI 114490 in the susceptible line $\mathrm{OH} 88119$ was performed to determine the role of SlPub24 in resistance to race T3. Two constructs were created for genetic transformation. The first construct, SlPub24PI (Fig. S2a), was developed by inserting the fragment of the coding sequence (CDS) of SlPub24 with a His tag into the vector pBI121 ${ }^{59}$. The CDS fragment was amplified from the cDNA of PI 114490 using gene-specific primers (Table S1). The second construct, pSIPub24PI (Fig. S2b), was generated by inserting a fragment of $3831 \mathrm{bp}$ including the promoter, $5^{\prime} \mathrm{UTR}, \mathrm{CDS}$, and $3^{\prime} \mathrm{UTR}$ of the SlPub24 gene into pBI121 with excision of the CaMV $35 \mathrm{~S}$ promoter. The DNA fragment was amplified from the genomic DNA of PI 114490 using a pair of specific primers (Table S1). Both destination constructs were confirmed by sequencing, separately transformed into $A$. tumefaciens strain C58 using electroporation, and then separately transformed into the susceptible tomato line $\mathrm{OH} 88119$ using previously described methods ${ }^{60}$ with slight modifications. The transgenic tomato lines were verified by PCR using primers (Table S1) specific to each construct.

\section{Mutation of the SIPub24 gene in the resistant line PI 114490 using the CRISPR/Cas9 editing system}

The CRISPR/Cas9 vector ${ }^{61}$ with modification by replacing the Arabidopsis U6 gene promoter with the tomato U6 gene promoter was kindly provided by Dr. Xia Cui at the Institute of Vegetables and Flowers at the Chinese Academy of Agricultural Sciences (Beijing, China). Two target sites (sgRNA1 and sgRNA2) of 20 nucleotides in the U-box domain separated by $57 \mathrm{bp}$ were selected using CRISPR-P (http://cbi.hzau.edu.cn/cgi-bin/CRISPR). The CRISPR/Cas9 construct was generated following a previous description ${ }^{61}$. The vectors were introduced into $A$. tumefaciens strain C58 through electroporation and transformed into tomato line PI 114490 using the methods described above. All regenerated T0 lines were subjected to Cas9 detection by PCR using specific primers (Table S1), and only lines containing Cas9 were retained for further detection of mutations in the SlPub24 gene region by sequencing PCR products amplified using a forward primer to the left of sgRNA1 and a reverse primer to the right of sgRNA2 (Table S1). Only homozygous mutants from the T2 generation were used for disease evaluation.

\section{Subcellular localization}

The open reading frame of SlPub24 without the termination codon was inserted into the modified $\mathrm{pSu}$ per1300 plasmid containing GFP protein at the Xba I and Kpn I (New England BioLabs, MA, USA) sites to generate the vector. The construct was transformed into A. tumefaciens by heat shock and into tomato protoplast and onion epidermal cells by PEG and gene gun, respectively. DAPI staining solution (Huayueyang Biotechnology Co., Beijing, China) was added to the transfected protoplasts for 5-10 min, followed by washing with buffer solution 2-3 times. GFP fluorescence was monitored by excitation at $488 \mathrm{~nm}$, and the DAPI-stained nuclei were observed by excitation at $360 \mathrm{~nm}$ with an argon laser using an Olympus BX 51 fluorescence microscope (Olympus Corporation, Tokyo, Japan). 


\section{Disease evaluation}

$X$. euvesicatoria pv. euvesicatoria (race T1) strain Xcv110c, X. vesicatoria (race T2) strain Xv1111, X. euvesicatoria pv. perforans race T3 strain $X v 829$, and $X$. euvesicatoria pv. perforans race T4 strain scott1 were kindly provided by Dr. Jeffery Jones at the University of Florida. Inoculum preparation and inoculation were performed according to our previous methods ${ }^{11}$. Both percent diseased leaf area and bacterial population were adopted as parameters for evaluating plant resistance. The percent diseased leaf area was measured using the leaf-byleaf approach with image analysis software ASSESS V2.0 ${ }^{11}$ 7 days post inoculation (dpi). Bacterial populations in inoculated leaves of the tomato lines were determined by the dilution plate method ${ }^{11}$ at $9 \mathrm{dpi}$. Three inoculated $0.2 \mathrm{~cm}^{2}$ leaf discs from each plant and at least 30 plants for each genotype were sampled to monitor the bacterial population. The data were analyzed using SPSS software (IBM SPSS Statistics, version 20, New York, USA) with one-way analysis of variance (ANOVA) followed by Duncan's test for multiple comparisons. Probability values less than 5\% $(P<0.05)$ were considered significant.

\section{Cell death detection}

Trypan blue staining was performed to visualize cell death in the leaves of the tomato plants after inoculation with $X v 829$. The inoculated leaves were boiled in trypan blue staining solution $(10 \mathrm{ml}$ lactic acid, $10 \mathrm{ml}$ glycerol, $10 \mathrm{~g}$ phenol, and $10 \mathrm{mg}$ trypan blue dissolved in $10 \mathrm{ml}$ $\mathrm{ddH}_{2} \mathrm{O}$ ) for $3 \mathrm{~min}$ and stained overnight in chloral hydrate

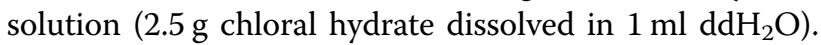
The stained plant leaves were mounted in 70\% glycerol for observation. Photographs were taken by a Nikon D3000 Digital SLR camera (Nikon, Tokyo, Japan).

\section{Measurement of SICWINV1 activity and salicylic acid content}

Leaf samples were collected from three plants of each genotype at 0 and $192 \mathrm{~h}$ post inoculation with T3 strain $X v 829$. For the measurement of SICWINV1 activity, leaf tissues were ground in liquid nitrogen and homogenized in $2 \mathrm{ml} / \mathrm{g}$ extraction buffer $(50 \mathrm{mM}$ citric acid, $250 \mathrm{mM}$ sorbitol, $10 \mathrm{mM} \mathrm{MgCl} 2,10 \mathrm{mM} \mathrm{KCl}$, and $1 \mathrm{mM} \mathrm{PMSF}$, $\mathrm{pH}$ 6.0). After centrifugation $\left(8500 \mathrm{~g}, 10 \mathrm{~min}, 4^{\circ} \mathrm{C}\right)$, the pellets were washed once $(10 \mathrm{~min})$ with extraction buffer containing $1 \%$ Triton X-100 and twice with extraction buffer only. The cell wall pellets were resuspended in $1 \mathrm{ml} / \mathrm{g}$ assay buffer $(20 \mathrm{mM}$ triethanolamine, $7 \mathrm{mM}$ citric acid, and $1 \mathrm{mM}$ PMSF, $\mathrm{pH} 4.6$ ) and used for the determination of SICWINV1 activity. The activity was monitored by mixing $20-100 \mu \mathrm{l}$ of invertase preparation, $100 \mu \mathrm{l}$ of sucrose (100 $\mathrm{mM}$ in assay buffer), and the assay buffer up to a volume of $300 \mu \mathrm{l}$. After incubation at $37^{\circ} \mathrm{C}$ for $30 \mathrm{~min}$, invertase activity was measured by enzymatic determination of the released glucose in a coupled enzymatic-optical assay with hexokinase and glucose-6phosphate dehydrogenase, according to the Jansen method $^{62}$. Determination of salicylic acid content was performed by Jiaxing Metware Metabolic Biotechnology Company (Zhejiang, China).

\section{Identification of proteins that interact with SIPUB24 using yeast two-hybrid assay}

The yeast two-hybrid $(\mathrm{Y} 2 \mathrm{H})$ assay was performed following the instructions in the Matchmaker GAL4 TwoHybrid System \& Libraries User Manual (Clontech Laboratories, Inc., CA, USA). The full-length SlPub24 open reading frame was amplified from cDNA of PI 114490 using gene-specific primers (Table S1) and cloned into the pGBKT7 bait vector ${ }^{63}$. The bait vector pGBKT7SIPUB24 and the pGADT7 prey vector (cDNA library) were cotransformed into the yeast (Saccharomyces cerevisiae) strain AH109 by the PEG/LiOAc method. Selfactivation of each protein was inhibited by 3 -amino-1,2,4triazole (3-AT) at different concentrations depending on the gene. The cotransformed yeast strains were first grown on selective medium lacking Leu and $\operatorname{Trp}(\mathrm{SD} /$ Leu-Trp) and then transferred to SD/-Trp-Leu-His/X- $\alpha$ GAL. Protein interactions were determined by the appearance of blue color 3-5 days after incubation at $30^{\circ} \mathrm{C}$.

Plasmid DNA of positive colonies was isolated using a Yeast High-Purity Plasmid Extraction Kit (Aidlab Biotechnologies, Beijing, China). The cDNA inserts were amplified (primers shown in Table S1), and the resulting PCR products were sequenced. The obtained sequences were blasted to the tomato genome sequence database in NCBI (https://www.ncbi.nlm.nih.gov/) and SGN (https:// solgenomics.net/) to verify the genes. The full-length sequence of each gene was obtained from SGN and used for gene-specific primer design. Candidate genes were amplified from the cDNA of PI 114490 using genespecific primers (Table S1), and the yeast two-hybrid method described above was used to verify their interactions with SIPUB24.

\section{Bimolecular fluorescence complementation (BiFC) assay}

The ORFs of SlPub24 and SlCWP amplified from cDNA of PI 114490 without stop codons were separately cloned into the pSY-NE and pSY-CE vectors using the Seamless Assembly Cloning Kit (Takara). The fusion vectors were transferred into A. tumefaciens strain GV3101 using heatshock transformation. Then, strain GV3101 containing fusion proteins was incubated at $28^{\circ} \mathrm{C}$ for $12-18 \mathrm{~h}$ and resuspended in infiltration buffer $(0.1 \mathrm{mM}$ acetosyringone, $10 \mathrm{mM} \mathrm{MgCl}$, and $10 \mathrm{mM} \mathrm{MES)} \mathrm{at} \mathrm{concentra-}$ tions of $0.8-1.2\left(\mathrm{OD}_{600}\right)$. Bacteria carrying the pSY-NE construct were mixed with bacteria carrying the $\mathrm{PSY}-\mathrm{CE}$ 
construct as well as GV3101 carrying P19 at a 1:1:1 (v/v) ratio and coinfiltrated into the leaves of six-week-old seedlings of $N$. benthamiana. The yellow fluorescent protein (YFP) signal was detected using an Olympus BX 51 fluorescence microscope (Olympus Corporation) 2 days after infiltration.

\section{Split luciferase complementation (SLC) assay}

The SLC assay was performed as previously described ${ }^{64}$. Constructs of SICWP-cLUC and SIPUB24-nLUC were cotransformed into $N$. benthamiana leaves and expressed for $48 \mathrm{~h}$. The abaxial sides of leaves were sprayed with $1 \mathrm{mM}$ beetle luciferin (Promega, WI, USA), and the signal was captured using a Photek camera (HRPCS5, Photek, UK).

\section{Protein degradation assay with MG132 treatment}

The plasmids p1300SIPUB24-Myc and p1300SICWPFlag were coexpressed with the P19 plasmid by agroinfiltration in the leaves of $N$. benthamiana. MG132 $(50 \mu \mathrm{M})$ was infiltrated into the leaf tissue before harvest, and DMSO was used as the control. Tissues were harvested 2 days after infiltration for protein extraction using the Plant Protein Extraction Kit (CWBIO, Beijing, China) following the manufacturer's instructions. Western blotting was performed as described previously ${ }^{65}$. Anti-Flag and anti-Myc (CWBIO) were diluted 1:2000. The total protein concentration was monitored by Coomassie brilliant blue (CBB) staining.

\section{Statistical analysis}

All samples were analyzed in triplicate, and the data are expressed as the mean \pm standard deviation unless noted otherwise. Statistical significance was determined using Student's $t$ test at the $0.05\left(^{*}\right)$ and $0.01(* *)$ levels. All experiments were conducted at least twice with three biological replicates each time.

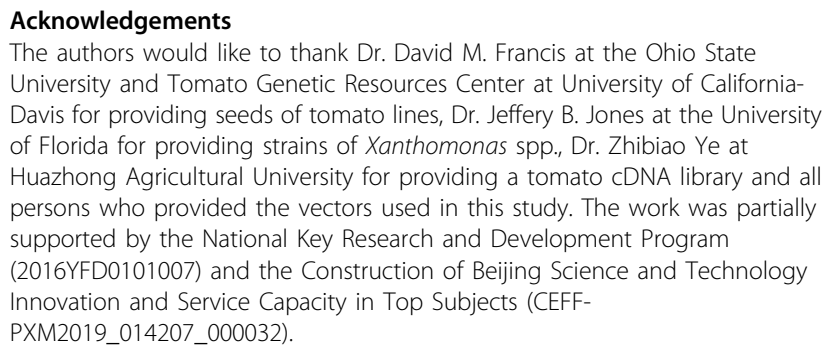

\section{Author contributions}

X.L. and W.Y. conceived and designed the research. X.L., G.M., M.W., and Y.Z. performed the experiments. X.L., Z.Q., and Y.Z. analyzed the data. X.L. and W.Y. wrote the manuscript. All authors read and approved the manuscript.

\section{Conflict of interest}

The authors declare that they have no conflict of interest.
Supplementary Information accompanies this paper at (https://doi.org/ 10.1038/s41438-021-00468-4).

Received: 12 June 2020 Revised: 2 December 2020 Accepted: 3 December 2020

Published online: 01 February 2021

\section{References}

1. Jones, J. B., Lacy, G. H., Bouzar, H., Stall, R. E. \& Schaad, N. W. Reclassification of the xanthomonads associated with bacterial spot disease of tomato and pepper. Syst. Appl. Microbiol. 27, 755-762 (2004).

2. Timisina, S. et al. Reclassification of Xanthomonas gardneri (ex Sutic 1957) Jones et al. 2006 as a later heterotypic synonym of Xanthomonas cynarae Trebaol et al. 2000 and description of X. cynarae pv. cynarae and X. cynarae pv. gardneri based on whole genome analyses. Int. J. Syst. Evol. Microbiol. 69, 343-349 (2019).

3. Constantin, E. C. et al. Genetic characterization of strains named as Xanthomonas axonopodis pv. dieffenbachiae leads to a taxonomic revision of the $X$. axonopodis species complex. Plant Pathol. 65, 792-806 (2016).

4. Wang, Y., Zhang, Y., Gao, Z. \& Yang, W. Breeding for resistance to tomato bacterial diseases in China: challenges and prospects. Hortic. Plant J. 4 193-207 (2018).

5. Adhikari, P. Adhikari, T. B., Louws, F. J. \& Panthee, D. R. Advances and challenges in bacterial spot resistance breeding in tomato (Solanum lycopersicum L.). Int. J. Mol. Sci. 21, 1734 (2020).

6. Li, N., Zhang, X. \& Yang, W. Marker-assisted development and characterization of near-isogenic lines carrying the Rx4 gene for hypersensitive resistance to Xanthomonas euvesicatoria pv. perforans race T3 in tomato. Mol. Breed. 39, 172 (2019).

7. Scott, J. W., Hutton, S. F., Shekasteband, R., Sim, S. C. \& Francis, D. M. Identification of tomato bacterial spot race T1, T2, T3, T4, and Xanthomonas gardneri resistance QTLs derived from PI 114490 populations selected for race T4. Acta Hortic. 1069, 53-58 (2015).

8. Scott, J. W., Francis, D. M., Miller, S. A., Somodi, G. C. \& Jones, J. B. Tomato bacterial spot resistance derived from PI 114490; Inheritance of resistance to race $\mathrm{T} 2$ and relationship across three pathogen races. J. Am. Soc. Hortic. Sci. 128, 698-703 (2003).

9. Bernal, E., Liabeuf, D. \& Francis, D. M. Evaluating quantitative trait locus resistance in tomato to multiple Xanthomonas spp. Plant Dis. 104, 423-429 (2020).

10. Hutton, S. F. et al. Identification of QTL associated with resistance to bacterial spot race T4 in tomato. Theor. Appl. Genet. 121, 1275-1287 (2010).

11. Sun, H., Wei, J., Zhang, J. \& Yang, W. A comparison of disease severity measurements using image analysis and visual estimates using a category scale for genetic analysis of resistance to bacterial spot in tomato. Eur. J. Plant Pathol. 139, 125-136 (2014).

12. Sun, $\mathrm{H}$. et al. QTL analysis of resistance to bacterial spot race T3 in tomato. Acta Hortic. Sin. 38, 2297-2308 (2011).

13. Yang, W., Miller, S. A., Francis, D. M., Scott, J. W. \& Jones, J. B. Mining tomato genome sequence databases for molecular markers: application to bacteria resistance and marker assisted selection. Acta Hortic. 695, 241-249 (2005).

14. Du, H. S., Wang, Y. Q., Yang, J. J. \& Yang, W. C. Comparative transcriptome analysis of resistant and susceptible tomato lines in response to infection by Xanthomonas perforans race T3. Front. Plant Sci. 6, 1173 (2015).

15. Du, H., Li, W., Wang, Y. \& Yang, W. Identification of genes differentially expressed between resistant and susceptible tomato lines during time-course interactions with Xanthomonas perforans race T3. PLoS One 9 e93476 (2014).

16. Zeng, L. R. et al. Spotted leaf11, a negative regulator of plant cell death and defense, encodes a U-box/armadillo repeat protein endowed with E3 ubiquitin ligase activity. Plant Cell 16, 2795-2808 (2004).

17. Yin, Z. C. et al. Characterizing rice lesion mimic mutants and identifying a mutant with broad-spectrum resistance to rice blast and bacterial blight. Mol. Plant Microbe Interact. 13, 869-876 (2000)

18. Li, W. et al. The U-Box/ARM E3 ligase PUB13 regulates cell death, defense, and flowering time in Arabidopsis. Plant Physiol. 159, 239-250 (2012).

19. Liu, J. et al. The U-Box E3 ligase SPL11/PUB13 is a convergence point of defense and flowering signaling in plants. Plant Physiol. 160, 28-37 (2012).

20. Trujillo, M., Ichimura, K., Casais, C. \& Shirasu, K. Negative regulation of PAMPtriggered immunity by an E3 ubiquitin ligase triplet in Arabidopsis. Curr. Biol. 18, 1396-1401 (2008) 
21. Stegmann, M. et al. The ubiquitin ligase PUB22 targets a subunit of the exocyst complex required for PAMP-triggered responses in Arabidopsis. Plant Cell 24, 4703-4716 (2012).

22. He, Q. et al. U-box E3 ubiquitin ligase PUB17 acts in the nucleus to promote specific immune pathways triggered by Phytophthora infestans. J. Exp. Bot. 66, 3189-3199 (2015).

23. Yang, C. W. et al. The E3 ubiquitin ligase activity of Arabidopsis PLANT U-BOX17 and its functional tobacco homolog ACRE276 are required for cell death and defense. Plant Cell 18, 1084-1098 (2006).

24. Kirsch, C., Logemann, E., Lippok, B., Schmelzer, E. \& Hahlbrock, K. A highly specific pathogen-responsive promoter element from the immediate-early activated CMPG1 gene in Petroselinum crispum. Plant J. 26, 217-227 (2001).

25. Navarro, L. et al. The transcriptional innate immune response to flg22. interplay and overlap with Avr gene-dependent defense responses and bacterial pathogenesis. Plant Physiol. 135, 1113-1128 (2004).

26. Zhu, $Y$. et al. E3 ubiquitin ligase gene CMPG1-V from Haynaldia villosa $L$. contributes to powdery mildew resistance in common wheat (Triticum aestivum L.). Plant J. 84, 154-168 (2015).

27. Gonzalez-Lamothe, R. et al. The U-Box protein CMPG1 is required for efficient activation of defense mechanisms triggered by multiple resistance genes in tobacco and tomato. Plant Cell 18, 1067-1083 (2006).

28. Lee, D. H., Choi, H. W. \& Hwang, B. K. The pepper E3 ubiquitin ligase RING1 gene, CaRING1, is required for cell death and the salicylic acid-dependent defense response. Plant Physiol. 156, 2011-2025 (2011).

29. Han, P.-L. et al. The apple U-box E3 ubiquitin ligase MdPUB29 contributes to activate plant immune response to the fungal pathogen Botryosphaeria dothidea. Planta 249, 1177-1188 (2019).

30. Han, P.-L. et al. BTB-BACK domain E3 ligase MdPOB1 suppresses plant pathogen defense against Botryosphaeria dothidea by ubiquitinating and degrading MdPUB29 protein in apple. Plant Cell Physiol. 60, 2129-2140 (2019).

31. Liu, X., Geng, X., Zhang, H., Shen, H. \& Yang, W. Association and genetic identification of loci for four fruit traits in tomato using InDel markers. Front. Plant Sci. 8, 1269 (2017).

32. Cantu, D., Vicente, A. R., Labavitch, J. M., Bennett, A. B. \& Powell, A. L. T. Strangers in the matrix: plant cell walls and pathogen susceptibility. Trends Plant Sci. 13, 610-617 (2008).

33. Harhouri, K. et al. MG132-induced progerin clearance is mediated by autophagy activation and splicing regulation. EMBO Mol. Med. 9, 1294-1313 (2017).

34. Zhao, $\mathrm{H}$. et al. Melatonin regulates carbohydrate metabolism and defenses against Pseudomonas syringae pv. tomato DC3000 infection in Arabidopsis thaliana. J. Pineal Res. 59, 109-119 (2015).

35. Wang, Y. Q., Zhang, X. F., Li, N. \& Liu, X. Comparison of cellular responses to Xanthomonas perforans infection between resistant and susceptible tomato accessions. J. Plant Physiol. 209, 105-114 (2017).

36. Sim, S. C. et al. Association analysis for bacterial spot resistance in a directionally selected complex breeding population of tomato. Phytopathology 105, 1437-1445 (2015)

37. Frary, A. et al. fw2.2: a quantitative trait locus key to the evolution of tomato fruit size. Science $\mathbf{2 8 9}, \mathbf{8 5 - 8 8}$ (2000)

38. Nesbitt, T. C. \& Tanksley, S. D. Comparative sequencing in the genus Lycopersicon: implications for the evolution of fruit size in the domestication of cultivated tomatoes. Genetics 162, 365-379 (2002)

39. $Y e$, J. et al. Tomato SD1, encoding a kinase interacting protein, is a major locus controlling stem development. J. Exp. Bot. https://doi.org/10.1093/jxb/eraa144 (2020).

40. Roemer, P. et al. Plant pathogen recognition mediated by promoter activation of the pepper Bs3 resistance gene. Science 318, 645-648 (2007).

41. Roemer, P. et al. Recognition of AvrBs3-like proteins is mediated by specific binding to promoters of matching pepper Bs3 alleles. Plant Physiol. 150 1697-1712 (2009).

42. Roemer, P., Recht, S. \& Lahaye, T. A single plant resistance gene promoter engineered to recognize multiple TAL effectors from disparate pathogens. Proc. Natl Acad. Sci. USA 106, 20526-20531 (2009).
43. Vicente, M. R.-S. \& Plasencia, J. Salicylic acid beyond defence: its role in plant growth and development. J. Exp. Bot. 62, 3321-3338 (2011).

44. Klessig, D. F., Choi, H. W. \& Dempsey, D. M. A. Systemic acquired resistance and salicylic acid: past, present, and future. Mol. Plant Microbe Interact. 31, 871-888 (2018).

45. Dempsey, D. M. A., Vlot, A. C., Wildermuth, M. C. \& Klessig, D. F. Salicylic acid biosynthesis and metabolism. Arabidopsis Book. 9, e0156-e0156 (2011).

46. Gao, Q.-M., Zhu, S., Kachroo, P. \& Kachroo, A. Signal regulators of systemic acquired resistance. Front. Plant Sci. 6, 228 (2015).

47. Khan, M. I. R., Fatma, M., Per, T. S., Anjum, N. A. \& Khan, N. A. Salicylic acid induced abiotic stress tolerance and underlying mechanisms in plants. Front. Plant Sci. 6, 462 (2015).

48. Seyfferth, C. \& Tsuda, K. Salicylic acid signal transduction: the initiation of biosynthesis, perception and transcriptional reprogramming. Front. Plant Sci. 5, 697 (2014).

49. Herrera-Vasquez, A., Salinas, P. \& Holuigue, L. Salicylic acid and reactive oxygen species interplay in the transcriptional control of defense genes expression. Front. Plant Sci. 6, 171 (2015).

50. Kim, D. S. \& Hwang, B. K. An important role of the pepper phenylalanine ammonia-lyase gene (PAL1) in salicylic acid-dependent signalling of the defence response to microbial pathogens. J. Exp. Bot. 65, 2295-2306 (2014).

51. Shine, M. B. et al. Cooperative functioning between phenylalanine ammonia lyase and isochorismate synthase activities contributes to salicylic acid biosynthesis in soybean. N. Phytol. 212, 627-636 (2016).

52. Wang, J. et al. The E3 ligase OsPUB15 interacts with the receptor-like kinase PID2 and regulates plant cell death and innate immunity. BMC Plant Biol. 15, 49 (2015).

53. Ishikawa, K. et al. Bacterial effector modulation of host E3 ligase activity suppresses PAMP-triggered immunity in rice. Nat. Commun. 5, 5430 (2014).

54. Link, M., Rausch, T. \& Greiner, S. In Arabidopsis thaliana, the invertase inhibitors AtCNIF1 and 2 exhibit distinct target enzyme specificities and expression profiles. FEBS Lett. 573, 105-109 (2004).

55. Kumar, S., Stecher, G., Li, M., Knyaz, C. \& Tamura, K. MEGA X: molecular evolutionary genetics analysis across computing platforms. Mol. Biol. Evol. 35, 1547-1549 (2018)

56. Cui, J. et al. Tomato MYB49 enhances resistance to Phytophthora infestans and tolerance to water deficit and salt stress. Planta 248, 1487-1503 (2018).

57. Livak, K. J. \& Schmittgen, T. D. Analysis of relative gene expression data using real-time quantitative PCR and the 2(T)(-Delta Delta C) method. Methods $\mathbf{2 5}$ 402-408 (2001).

58. Hull, G. A. \& Devic, M. The beta-glucuronidase (gus) reporter gene system: gene fusions; spectrophotometric, fluorometric, and histochemical detection Methods Mol. Biol. 49, 125-141 (1995).

59. Chen, P. Y., Wang, C. K., Soong, S. C. \& To, K. Y. Complete sequence of the binary vector pBl121 and its application in cloning T-DNA insertion from transgenic plants. Mol. Breed. 11, 287-293 (2003).

60. Fillatti, J. J., Kiser, J., Rose, R. \& Comai, L. Efficient transfer of a glyphosafe tolerance gene into tomato using a binary Agrobacterium tumefaciens vector. Bio-Technol. 5, 726-730 (1987).

61. Xing, H.-L. et al. A CRISPR/Cas9 toolkit for multiplex genome editing in plants. BMC Plant Biol. 14, 327 (2014).

62. Jansen, A. Modifying post-harvest sucrose loss in sugar beet: assessment of transgenic approaches. PhD thesis. University at Heidelberg, Heidelberg, Germany, (2009).

63. Chien, C. T., Bartel, P. L., Sternglanz, R. \& Fields, S. The two-hybrid systems: a methods to identify and clone genes for proteins that interact with a protein of interest. Proc. Natl Acad. Sci. USA 88, 9578-9582 (1991).

64. Chen, $\mathrm{H}$. et al. Firefly luciferase complementation imaging assay for proteinprotein interactions in plants. Plant Physiol. 146, 368-376 (2008).

65. MacPhee, D. J. Methodological considerations for improving Western blot analysis. J. Pharmacol. Toxicol. Methods 61, 171-177 (2010). 